\title{
Effets bénéfiques de rhizobactéries sur les plantes: exemple des Pseudomonas spp fluorescents
}

\author{
P Lemanceau \\ INRA. DUCUIVISISTATIN \\ 17. Fue Suig - F.V. IE 40 \\ 21034 C : C C EX

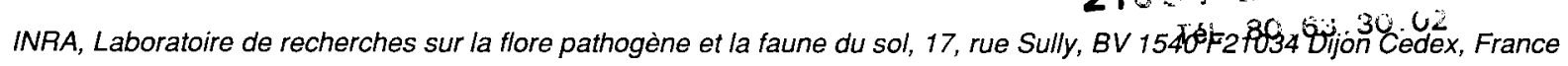
MINISTËRE DE '.'AGRICULTURE

(Reçu le 4 novembre 1991; accepté le 17 mars 1992)

\begin{abstract}
Résumé - Parmi les rhizobactéries non symbiotiques, les Pseudomonas spp fluorescents font l'objet d'une attention particulière. L'inoculation des plantes à l'aide de certaines souches de Pseudomonas spp s'accompagne en effet d'une augmentation significative du rendement de la culture. Celle-ci résulte de la stimulation de la croissance des plantes et de leur protection contre des microrganismes pathogènes. Deux types de mécanismes sont responsables de ces effets bénéfiques. L'un concerne la modification des équilibres microbiens au niveau de la rhizosphère, l'autre la modification du métabolisme et de la physiologie de la plante. Ainsi, la compétition et l'antibiose exercées par les Pseudomonas spp réduisent la densité et l'activité néfaste de microrganismes pathogènes. Les Pseudomonas spp affectent également la croissance des plantes en améliorant leur alimentation minérale et en synthétisant des substances de croissance. Ces bactéries peuvent enfin provoquer une augmentation du niveau de résistance des plantes aux maladies. Les effets bénéfiques de l'inoculation bactérienne ne se manifestent que si certaines conditions sont réunies. En premier lieu, il est nécessaire de sélectionner des souches efficaces. Cette efficacité repose sur la synthèse de métabolites particuliers (sidérophores, antibiotiques, substances de croissance, lipopolysaccharides, etc) et sur la bonne colonisation racinaire des Pseudomonas spp. Ces souches doivent, de plus, être introduites dans des sols qui présentent des caractéristiques physico-chimiques et biologiques favorables à l'expression des activités bactériennes intéressantes. La meilleure compréhension des mécanismes et des conditions d'expression des effets bénéfiques de l'inoculation bactérienne permet maintenant d'envisager d'améliorer l'efficacité de la bactérisation et surtout la reproductibilité des résultats obtenus.
\end{abstract}

plant growth promoting rhizobacteria / rhizosphère / lutte biologique / antagonisme microbien / sidérophore / antibiotique / substance de croissance / résistance induite / inoculation bactérienne

Summary - Beneficial effects of rhizobacteria on plants: example of fluorescent Pseudomonas spp. Among the non symbiotic rhizobacteria, much attention has been given to fluorescent Pseudomonas spp. As a matter of fact, inoculation of plants with specific Pseudomonas spp strains increases crop yields significantly. This increase is related to the promotion of plant growth and to the plant protection against pathogenic microorganisms. Two main mechanisms are responsible for these beneficial effects. One is due to the modification of the microbial balance at the rhizosphere level, the other is due to the modification of the metabolism and the physiology of the inoculated plant. So, competition and antibiosis performed by fluorescent Pseudomonas spp reduce the density and the deleterious activity of pathogenic microorganisms. Fluorescent Pseudomonas spp strains also promote plant growth by improving their mineral nutrition and by synthetizing growth substances. Lastly, these bacteria may enhance the resistance level of inoculated plants toward pathogenic microorganisms. These beneficial effects are only expressed in some specific conditions. Efficient strains must first be selected. The efficacy of these strains is related to the synthesis of specific metabolites (siderophores, antibiotics, growth substances, lipopolysaccharides, etc) and to their good root colonization. Furthermore, the beneficial strains must be introduced in soils showing some physico-chemical and biological characteristics favorable to the expression of the beneficial bacterial activities. As progress is being made in the understanding of the mechanisms and of the factors affecting the beneficial effects of bacterisation, it is now possible to improve the efficacy and consistency of the yield promotion.

plant growth promoting rhizobacteria / rhizosphere / biological control / microbial antagonism / siderophore / antibiotic / growth substance / induced resistance / bacterial inoculation 


\section{INTRODUCTION}

Les rhizobactéries sont des bactéries qui présentent l'aptitude à coloniser les racines de façon intense (Schroth et Hancock, 1981, 1982). Les bactéries non symbiotiques répondant à cette définition appartiennent à différents genres et espèces dont les plus étudiés sont : Agrobacterium radiobacter, Azospirillum spp, Bacillus spp, Pseudomonas spp fluorescents (Kerr, 1972; Broadbent et al, 1977; Okon, 1985; Leong, 1986).

Les effets bénéfiques des rhizobactéries sont liés à leur position stratégique à l'interface solracine. En effet, le rhizoplan et la rhizophère sont le siège d'échanges intenses entre la plante et le milieu environnant (Curl, 1982). Ces échanges sont réciproques.

La plante libère des exsudats racinaires qui sont constitués de substances organiques carbonées et azotées : polysaccharides, acides organiques et protéines (Mench, 1985). Ces exsudats favorisent le développement de la microflore pathogène ou non. Ainsi, en réponse à l'apport énergétique représenté par les exsudats racinaires, des propagules fongiques se développent de façon saprophytique jusqu'à la racine qu'elles peuvent infecter et éventuellement parasiter (Schroth et Hildenbrand, 1964). De même, la densité des bactéries est plus élevée dans la rhizosphère que dans le sol distant des racines : il s'agit de «l'effet rhizosphère» (Foster et Rovira, 1978). La quantité et la composition des exsudats racinaires conditionnent également la nature des activités bactériennes (Loper et Schroth, 1986a). Ces activités résultent de la synthèse de métabolites tels que les sidérophores, antibiotiques, substances de croissance, acide cyanhydrique, lipopolysaccharides (Brown, 1974; Neilands et Leong, 1986; Fravel, 1988; Voisard et al, 1989; Van Peer et al, 1991).

Si la plante libère des composés organiques, à l'inverse elle prélève de l'eau et des éléments minéraux indispensables à son métabolisme. $\mathrm{Ce}$ prélèvement est d'ailleurs associé à l'extrusion de protons qui contribue à abaisser la valeur du $\mathrm{pH}$ de la rhizosphère (Bienfait, 1986). Les racines sont également capables d'absorber certaines molécules organiques, produites par les microrganismes présents dans la rhizosphère (Dommergues et Mangenot, 1970). Les échanges entre la plante et le sol sont influencés par les rhizobactéries et ce d'autant plus que leur densité et leur activité sont élevées. Cette influence se manifeste par une modification de la croissance de la plante et de la fréquence des infections fongiques de la racine. Selon les rhizobactéries présentes, ces modifications peuvent être positives ou négatives pour la plante. Leur étude a donc suscité l'intérêt de nombreux chercheurs.

L'étude des effets bénéfiques de la bactérisation, c'est-à-dire de l'apport de bactéries au sol ou en enrobage des semences, n'est pas récente puisque selon Cooper (1959) cette technique a été utilisée sur $10^{7}$ ha en Union Soviétique en 1958. Les bactéries utilisées appartenaient principalement aux espèces Azotobacter chroococcum et Bacillus megaterium var phosphaticum. Cependant, Mishutin et Naumova (1962) estimaient que ce traitement n'a engendré que des augmentations modestes de rendements et seulement sur 50 à $70 \%$ des surfaces. Malgré ces résultats, la bactérisation a ultérieurement fait l'objet d'expérimentations précises réalisées à petite échelle dans divers pays (Brown, 1974). En dépit de la rigueur de ces travaux, aucun résultat vraiment marquant n'a été obtenu, de telle sorte que Ecklund (1970) concluait sa thèse en ces termes : "Les résultats de cette étude n'encouragent pas à poursuivre de nouveaux essais sur l'inoculation avec des bactéries saprophytes non symbiotiques du rhizoplan de plantes cultivées".

Le manque d'effet bénéfique dû à la bactérisation pourrait être associé à la faible compétence rhizosphérique des bactéries introduites. En effet, Baker et Cook (1974) suggèrent que la microflore rhizosphérique est constituée d'un ensemble de microrganismes en équilibre. Si la souche introduite ne colonise pas la rhizosphère de façon agressive, son activité bénéfique ne peut s'exprimer, car l'équilibre microbien antérieur à l'inoculation se rétablit rapidement. Par contre, comme en atteste une série d'articles parus à partir de 1978 (Burr et al, 1978; Kloepper et Schroth, 1978; Kloepper et al, 1980abc; Stutz et al, 1986; Geels et al; 1986), l'utilisation de certaines souches de Pseudomonas spp fluorescents aptes à se maintenir et à se développer sur le système racinaire s'accompagne d'effets bénéfiques significatifs pour les plantes inoculées. À la suite de l'intérêt suscité par ces publications, une grande part du travail de recherche réalisé sur les rhizobactéries est maintenant effectuée sur des bactéries appartenant au groupe des Pseudomonas spp fluorescents qui inclut les espèces $P$ fluorescens et $P$ putida.

Au cours de cet article seront présentés les principaux effets bénéfiques induits par la bacté- 
risation avec des Pseudomonas spp fluorescents, puis les mécanismes responsables de ces effets et enfin les conditions nécessaires à l'expression de ces effets bénéfiques.

\section{PRÉSENTATION DES EFFETS BÉNÉFIQUES}

La finalité de la bactérisation est d'augmenter le rendement des cultures. Seules certaines souches semblent présenter cette capacité (Weller, 1988). Elles ont été appelées «Plant Growth Promoting Rhizobacteria» (PGPR) par Kloepper et Schroth (1978).

L'augmentation de rendement d'une culture bactérisée résulte de 2 effets bénéfiques principaux : la stimulation de croissance des plantes et la protection des plantes contre les maladies d'origine tellurique. D'autres effets bénéfiques ont également été décrits. Ainsi certaines souches de Pseudomonas stimulent la germination des graines. D'autres influencent positivement les interactions entre les microrganismes symbiotiques (Rhizobium, Bradyrhizobium; champignons mycorhiziens) et la plante hôte.

\section{Stimulation de la croissance des plantes}

De nombreux travaux font état d'une stimulation de la croissance des plantes et du rendement des cultures après bactérisation. Comme en atteste le tableau 1, ces études ont été réalisées avec des plantes hôtes et des conditions expérimentales variées. Il apparaît clairement que l'augmentation de rendement, observée en conditions normales de production, est toujours inférieure à l'augmentation de croissance des plantes cultivées en conditions contrôlées (culture en pots et en serre ou en chambre climatisée).

\section{Protection des plantes contre les maladies d'origine tellurique}

L'utilisation de bactéries pour lutter contre les maladies d'origine tellurique a fait l'objet de nombreuses synthèses bibliographiques (Schroth et Hancock, 1982; Leong, 1986; Neilands et Leong, 1986; Fravel, 1988) auxquelles le lecteur pourra se reporter pour plus de détails.

Les modèles biologiques utilisés mettent en jeu différentes souches de Pseudomonas et différentes maladies (tableau II). Les problèmes pa- thologiques les plus étudiés sont : les fontes de semis, les fusarioses, le piétin échaudage et les pourritures racinaires.

Même si les travaux de lutte biologique sont très nombreux, il est regrettable de constater que seuls quelques uns évaluent l'efficacité de cette lutte en termes d'augmentation de rendement (Kloepper et al, 1980c; Suslow et Schroth, 1982b; Saktivel et Gnanamamickam, 1987; Weller et Cook, 1986; Xu et Gross, 1986b; Leeman et al, 1991; Lemanceau et Alabouvette, 1991). La plupart des essais sont en effets réalisés en conditions contrôlées ou sont arrêtés avant la récolte.

\section{Autres effets bénéfiques}

\section{Stimulation de la germination}

Une des composantes du rendement agronomique des grandes cultures est la densité du peuplement végétal. Or, cette densité est liée à la faculté et à l'énergie germinatives des semences. Certaines souches bactériennes, appartenant en particulier au groupe des Pseudomonas spp fluorescents, semblent améliorer la germination des graines lorsque les conditions d'environnement sont défavorables. Ainsi Kloepper et al (1986) ont montré que le taux de germination de graines de colza, semées dans un sol froid et battant, pouvait être significativement augmenté grâce à l'inoculation par certaines souches bactériennes. De même Höfte et al (1991) ont enregistré une augmentation significative du taux de germination de semences de maïs soumises au froid après inoculation de 2 souches de Pseudomonas fluorescents. L'une d'entre elles a, de plus, permis de maintenir le pourcentage de germination d'un lot de semences âgé de 2 ans au même niveau que celui uniquement âgé de 1 an. Ces souches sont appelées «Emergence Promoting Rhizobacteria» (EPR) (Kloepper et al, 1986).

Récemment, Digat et al (1990) ont montré que certaines souches de Pseudomonas peuvent stimuler significativement la germination de graines de tomate même lorsque les conditions d'environnement ne semblent pas défavorables.

\section{Stimulation des interactions entre la microflore symbiotique et la plante hôte}

Certaines souches de Pseudomonas spp fluorescents stimulent la nodulation des légumi- 
Tableau I. Stimulation de la croissance des plantes et du rendement des cultures après inoculation de souches de Pseudomonas spp fluorescents.

\begin{tabular}{|c|c|c|c|c|c|}
\hline \multirow[t]{2}{*}{ Plante hôte } & \multicolumn{2}{|c|}{$\begin{array}{c}\text { Conditions } \\
\text { expérimentales }\end{array}$} & \multicolumn{2}{|c|}{$\begin{array}{l}\text { Augmentations } \\
\text { (\% du témoin) }\end{array}$} & \multirow[t]{2}{*}{ Références } \\
\hline & contrôlées & production & croissance & rendement & \\
\hline Beta vulgaris & $x$ & $x$ & 20 à 69 & 21 à 77 & Suslow et Schroth (1982b) \\
\hline $\begin{array}{l}\text { Brassica } \\
\text { campestris }\end{array}$ & $x$ & $\mathrm{X}$ & 22 à 65 & 7 à 19 & $\begin{array}{l}\text { Lifshitz et al (1987) } \\
\text { Kloepper et al (1988) }\end{array}$ \\
\hline Citrus sp & $x$ & & $\rightarrow 116$ & & Gardner et al (1984) \\
\hline Cucumis sativus & $x$ & & 36 à 58 & & Van Peer et Schippers (1989) \\
\hline Espèces florales & $x$ & & 18 à 41 & & Yuen et Schroth (1986) \\
\hline Lactuca sativa & $\begin{array}{l}x \\
x\end{array}$ & & $\begin{array}{l}38 \text { à } 86 \\
20 \text { à } 37\end{array}$ & & $\begin{array}{l}\text { Van Peer et Schippers (1989) } \\
\text { Digat et al (1990) }\end{array}$ \\
\hline $\begin{array}{l}\text { Lycopersicon } \\
\text { esculentum }\end{array}$ & $\begin{array}{l}x \\
x\end{array}$ & & $\begin{array}{l}25 \text { à } 93 \\
26 \text { à } 30\end{array}$ & & $\begin{array}{l}\text { Van Peer et Schippers (1989) } \\
\text { Digat et al (1990) }\end{array}$ \\
\hline $\begin{array}{l}\text { Malus sp } \\
\text { plantules } \\
\text { porte-greffes }\end{array}$ & $\begin{array}{l}x \\
x\end{array}$ & $X$ & $\begin{array}{l}23 \text { à } 40 \\
2 \text { à } 121\end{array}$ & & Caesar et Burr (1987) \\
\hline fruits & & $x$ & & 10 & Digat et al (1988) \\
\hline Oryza sativa & & $x$ & & 3 à 160 & $\begin{array}{l}\text { Saktivel et } \\
\text { Gnanamanikam (1987) }\end{array}$ \\
\hline Phaseolus vulgaris & $x$ & & 4 à 28 & & Lemanceau et Samson (1983) \\
\hline Raphanus sativus & $x$ & $x$ & & $\begin{array}{l}\longrightarrow 567 \\
\longrightarrow 200\end{array}$ & Kloepper et Schroth (1978) \\
\hline & $\begin{array}{l}x \\
x\end{array}$ & $x$ & $\begin{array}{l}83 \text { à } 320 \\
7 \text { à } 367\end{array}$ & 10-11 & $\begin{array}{l}\text { Bakker et al (1987) } \\
\text { Bakker et al (1986) } \\
\text { Burr et al (1978) }\end{array}$ \\
\hline $\begin{array}{l}\text { Solanum } \\
\text { tuberosum }\end{array}$ & $\begin{array}{l}x \\
x\end{array}$ & $\begin{array}{l}x \\
x \\
x\end{array}$ & $\begin{array}{l}\longrightarrow 550 \\
47 \text { à } 500\end{array}$ & $\begin{array}{l}10-15 \\
1 \text { à } 17 \\
17 \text { à } 37\end{array}$ & $\begin{array}{l}\text { Geels et Schippers (1983) } \\
\text { Geels et al (1986) } \\
\text { Kloepper et al (1980c) } \\
\text { Xu et Gross (1986b) }\end{array}$ \\
\hline Triticum sp & & $\mathrm{X}$ & & 2 à 26 & Weller et Cook (1986) \\
\hline
\end{tabular}

$X$ indique le type de conditions expérimentales utilisé.

$\rightarrow$ indique la valeur maximale de l'augmentation.

neuses. Ainsi, Grimes et Mount (1987) ont montré qu'une souche de $P$ putida augmente de façon significative la nodulation du haricot par
Rhizobium. De même, Polonenko et al (1987) ont montré que certaines rhizobactéries pouvaient améliorer la nodulation du soja par Brady- 
Tableau II. Protection des plantes contre différentes maladies d'origine tellurique, assurée par des souches de $P$ seudomonas spp fluorescents.

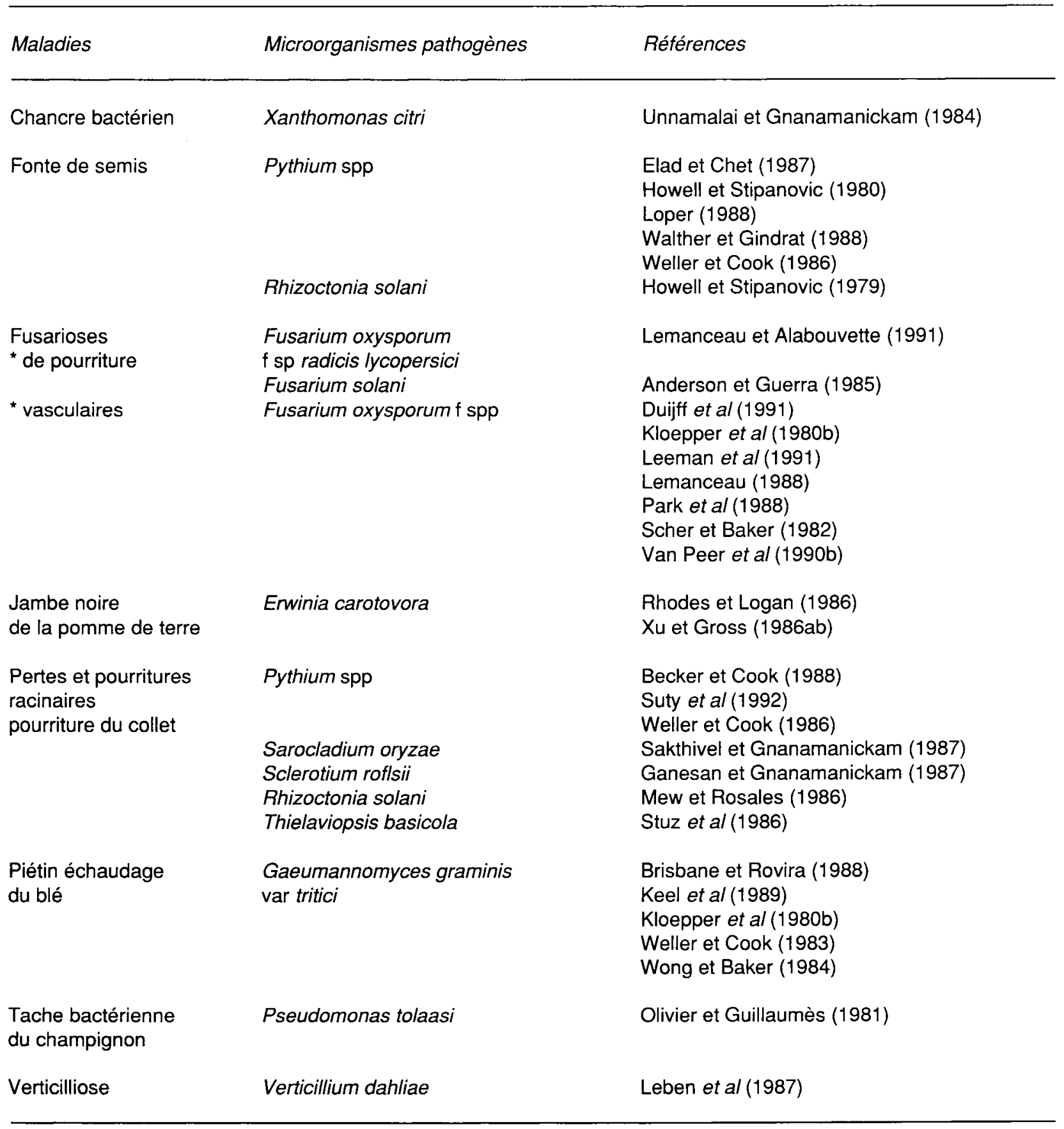

rhizobium. Ces souches sont appelées "Nodulating Promoting Rhizobacteria» (NPR). Toutes ces souches stimulent la croissance racinaires, produisent de l'acide indole acétique et sont pectinolytiques. Elles provoquent une augmentation de la masse de nodosités plutôt que de leur nombre (Zablotowicz, in Howell et Okon, 1987).

De même, certaines souches de bactéries influencent positivement la colonisation racinaire de la plante hôte par des endomycorhizes (von Alten et al, 1991) ou par des ectomycorhizes (Garbaye et Bowen, 1987). Mamoun et Olivier (1992) ont montré que certaines souches de Pseudomonas spp fluorescents améliorent la pérennité de l'association symbiotique entre l'ectomycorhize Tuber melanosporum et le noisetier. Par ailleurs, l'effet bénéfique, de l'inoculation mycorhizienne sur la plante, pourrait être stimulée par certaines rhizobactéries produc- 
trices de substances de croissance (Linderman et Paulitz, 1990) et par les rhizobactéries qui augmentent la solubilité des phosphates dans le sol (Raj et al, 1981). Ainsi l'association d'endomycorhizes et de Pseudomonas fluorescents s'accompagne d'une plus grande stimulation de la croissance de la plante que la seule inoculation bactérienne ou fongique (Meyer et Linderman, 1986; Oliveira et al, 1987).

\section{MÉCANISMES RESPONSABLES DES EFFETS BÉNÉFIQUES}

II apparaît clairement que l'un des problèmes majeurs liés à l'utilisation des Pseudomonas spp fluorescents est le manque de reproductibilité dans le temps et dans l'espace des effets bénéfiques enregistrés (Weller, 1988). Afin d'améliorer l'efficacité de la bactérisation, il est nécessaire de comprendre les mécanismes responsables des effets bénéfiques. Deux types de mécanismes se dégagent de l'ensemble des travaux publiés : l'un concerne la modification des équilibres microbiens, l'autre la modification du métabolisme et de la physiologie de la plante.

\section{Modification des équilibres microbiens}

Kloepper et Schroth (1981b) ont été les premiers à mettre en évidence l'effet bénéfique indirect d'une souche de Pseudomonas fluorescent sur la croissance des plantes. Ainsi, en condition monoxénique, la bactérisation de graines de radis ne provoque pas d'augmentation de croissance des plantes; alors que la même inoculation bactérienne, en conditions non gnotobiotiques, s'accompagne d'une stimulation significative de la croissance des plantes. Ces résultats les conduisent à éliminer l'hypothèse de l'influence directe de la souche de Pseudomonas sur la croissance des radis; ils suggèrent que l'effet bénéfique pourrait être lié à une modification des équilibres microbiens en faveur de la plante. Effectivement, ces mêmes auteurs ont, par ailleurs, mis en évidence que seules les souches de Pseudomonas, ayant provoqué une réduction de la densité des champignons et des bactéries Gram +, ont déterminé une augmentation de croissance des pommes de terre (Kloepper et Schroth, 1981c).

À la suite de ces travaux, de nombreux auteurs ont montré que les effets bénéfiques des Pseudomonas spp fluorescents sont associés à leur activité antagoniste à l'encontre de microrganismes qualifiés de pathogènes (Kloepper et al, 1980c; Suslow et Schroth, 1982b; Gardner et al, 1984; Bakker et al, 1986; Sakthivel et al, 1986; Cook et al, 1987; Elad et al, 1987). Ces microrganismes, qu'ils provoquent ou non des symptômes évidents, réduisent la croissance des plantes (Salt, 1979). La protection contre les microrganismes pathogènes par des Pseudomonas fluorescents antagonistes permet de soustraire la plante à leur activité néfaste. Selon l'efficacité de la protection biologique, la croissance des plantes bactérisées peut atteindre celle des plantes cultivées en absence de microrganismes pathogènes.

La relation entre cette protection et l'augmentation de croissance ou de rendement est très claire lorsque la plante est confrontée à des microrganismes qui déterminent des symptômes évidents et bien caractérisés (Fusarium oxysporum f spp, Gaeumannomyces graminis var tritici, Thielaviopsis basicola, etc). Ainsi il apparait que la réduction de la gravité de la maladie s'accompagne d'une augmentation de rendement de la culture bactérisée (Weller et Cook, 1986; Lemanceau et Alabouvette, 1991).

Sans symptôme apparent, l'effet néfaste des microrganismes pathogènes est occulté. D'ailleurs Hoy et Schneider (1988) proposent d'appeler ces microrganismes «pathogènes cryptiques". Ce qualificatif paraît plus approprié que celui de "pathogène mineur" donné par Salt (1979). Ces microrganismes provoquent, en effet, des réductions de rendement importantes (Schippers et al, 1987) et représentent une part non négligeable de la microflore rhizosphérique (Suslow et Schroth, 1982a). Cependant, en l'absence de témoin indemne de ces microrganismes, la réduction de croissance peut passer inaperçue. Pour associer l'effet bénéfique de certains Pseudomonas à la protection biologique qu'ils assurent, il est donc nécessaire de mettre en évidence l'effet néfaste et de caractériser les microrganismes en cause.

Ces microrganismes peuvent être parasites, c'est le cas de Pythiacées dont certaines provoquent des réductions significatives du rendement de différentes cultures: blé (Cook et al, 1987), canne à sucre (Hoy et Schneider, 1988), pêcher (Mircetich, 1971), pommier (Caesar et Burr, 1987), tulipe (Weststeijn et Meijer, 1991), culture hors-sol de concombre (Favrin et al, 1988; Stanghellini et al, 1988; Suty et al, 1992), d'épinard (Bates et Stanghellini, 1984) et de laitue (FunckJensen et Hockenull, 1983; Stanghellini et Kron- 
land, 1986). La mise en évidence du rôle des $P y$ thium dans ces réductions de rendement a été établie en 3 temps :

- relation entre la forte densité de Pythium dans le sol et la faible croissance des plantes (Cook et al, 1980);

- réduction de la croissance de la culture après infestation avec Pythium comparée à un témoin (Suty et al, 1992);

- compensation de cette perte de croissance par application de fongicides antipythiacées (Cook et al, 1980).

Une fois établie la réduction insidieuse de rendement due aux Pythiacées, différents auteurs ont alors associé la stimulation de croissance assurée par certaines souches de Pseudomonas spp fluorescents à l'activité antagoniste qu'ils exercent à l'encontre de ces champignons. En effet, ces bactéries se révèlent inefficaces lorsque les Pythium sont détruits après désinfection du sol ou application de fongicide (Weller et Cook, 1986; Becker et Cook, 1988).

La croissance des plantes peut également être réduite par l'activité néfaste de microrganismes pathogènes qualifiés de délétères ou "Deleterious Rhizo-Microorganisms" (DRMO) par Suslow et Schroth (1982a) et Schippers et al (1987). II peut s'agir de bactéries («Deleterious Rhizobacteria") (DRB) ou de champignons. Ainsi des Pseudomonas spp délétères, naturellement présents dans les cultures répétées de pomme de terre (Bakker et al, 1986a; Bakker et Schippers, 1987) ou artificiellement introduits lors de culture de blé (Elliott et Lynch, 1984) ou de betterave (Suslow et Schroth, 1982b), provoquent des réductions significatives de la croissance des plantes. Cette activité néfaste serait liée à la production de métabolites tels que l'acide cyanhydrique qui perturberait et inhiberait la croissance des plantes (Bakker et Schippers, 1987). La réduction de la densité de ces Pseudomonas délétères, soit par des techniques culturales appropriées - brûlage des pailles (Elliott et Lynch, 1984), rotation longue de pomme de terre (Bakker et al, 1987) - soit par l'utilisation de Pseudomonas fluorescents antagonistes (Suslow et Schroth, 1982b; Geels et Schippers, 1983; Schippers et al, 1985; Geels et al, 1986) s'accompagne d'une augmentation de la croissance des plantes et du rendement de la culture.

II apparaît donc clairement qu'un des mécanismes responsables des effets bénéfiques de certaines souches de Pseudomonas spp fluorescents repose sur l'activité antagoniste qu'ils exer- cent à l'encontre de microrganismes pathogènes inducteurs de maladies et de réductions de croissance. Parmi les modes d'action antagonistes de ces Pseudomonas fluorescents, la compétition et l'antibiose ont été particulièrement étudiées.

\section{Compétition}

Les interactions microbiennes sont conditionnées par la nature et l'intensité de la compétition entre microrganismes (Lockwood, 1981; Alabouvette, 1983). Cette compétition peut s'ins-taurer pour l'espace et pour les nutriments. Les Pseudomonas fluorescents antagonistes participent à ces 2 types de compétition.

Ainsi Suslow (1982) suggère que les PGPR seraient capables d'exclure les DRB de certaines niches écologiques où la production d'exsudats racinaires est importante. La répartition des bactéries n'est pas régulière le long de la racine, elle est plus dense aux endroits où la production d'exsudats est plus intense, comme par exemple aux sites d'émergence des racines secondaires et aux jonctions cellulaires (Bowen et Rovira, 1976). L'inoculation de PGPR réduirait l'installation de DRB à ces emplacements.

Même si le rôle de la compétition pour l'espace ne peut être complètement exclu, l'essentiel des travaux relatifs à la compétition, instaurée par les Pseudomonas fluorescents, porte sur la compétition trophique et, en particulier, sur la compétition pour le fer, comme en attestent les différentes synthèses bibliographiques relatives à ce sujet (Heming, 1986; Leong, 1986; Neilands et Leong, 1986; Loper et Buyer, 1991). Cet élément est en effet indispensable au métabolisme des microrganismes aérobies. Même s'il constitue le $4^{e}$ élément de l'écorce terrestre (Segalen, 1964), le fer est peu soluble et donc peu disponible dans les sols cultivés. En effet, dans les sols normalement aérés, le fer est surtout oxydé $\left(\mathrm{Fe}^{+++}\right)$. Aux valeurs de $\mathrm{pH}$ compatibles avec les cultures, le fer $\left(\mathrm{Fe}^{+++}\right)$se présente essentiellement sous forme d'hydroxyde ferrique $\left(\mathrm{Fe}(\mathrm{OH})_{3}\right)$ peu soluble (Lindsay et Schwab, 1981). Le produit de solubilité de $\mathrm{Fe}(\mathrm{OH})_{3}$ étant approximativement égal à $10^{-38} \mathrm{~mol}^{-1}$ la concentration calculée de $\mathrm{Fe}^{+++}$, à $\mathrm{pH}=7,7$ par exemple, atteint seulement $10^{-19}$ mol..$^{-1}$ (Lindsay, 1974). Cette concentration est insuffisante pour permettre la croissance optimale des microrganismes. Ainsi Simeoni et al (1987) ont montré que la concentration critique de fer $\left(\mathrm{Fe}^{+++}\right)$pour la germination des chlamydospores 
de Fusarium est comprise entre $10^{-19}$ et $10^{-22}$ mol.1-1. Pour acquérir cet élément indispensable mais peu soluble, les microrganismes ont développé une stratégie d'acquisition du fer qui repose sur la synthèse de sidérophores et de protéines membranaires réceptrices (Neilands, 1973; Leong, 1986). Cette synthèse n'a lieu qu'en situation de carence en fer (de Weger et al, 1986). Les sidérophores sont des métabolites de faible poids moléculaire qui présentent une forte affinité pour le fer $\left(\mathrm{Fe}^{+++}\right)$(Neilands, 1973). La structure de sidérophores produits par différentes souches de Pseudomonas spp fluorescents a été décrite (Teintze et al, 1981; Wendenbaum et al, 1983; Yang et Leong, 1984; Buyer et al, 1986; Van der Hofstad et al, 1986). Ils sont constitués d'une petite chaîne peptidique d'acides aminés $L$ et $D$ en alternance, liée à un groupe chromophore fluorescent jaune-vert et à un groupe succinamide. Une fois émis dans le milieu, ils chélatent le fer $\left(\mathrm{Fe}^{+++}\right)$. Ce complexe est reconnu de façon plus ou moins spécifique par des protéines membranaires réceptrices (Marugg et al, 1989; Bitter et al, 1991), traverse la membrane cellulaire, puis intègre la cellule où il est réduit (Leong, 1986). Cette stratégie est plus ou moins efficace selon les microrganismes. Tous les sidérophores ne présentent pas en effet la même affinité pour le fer $\left(\mathrm{Fe}^{+++}\right)$. Ainsi les Pseudomonas fluorescents produisent des sidérophores appelés pyoverdine (Meyer et Abdallah, 1978) ou pseudobactine (Teintze et al, 1981) qui forment avec le fer $\left(\mathrm{Fe}^{+++}\right)$un complexe (ferripyoverdine ou ferripseudobactine) dont la constante de stabilité est égale environ à $10^{32}$ (Meyer et Abdallah, 1978). Le fer chélaté par les pyoverdines ne peut pas être utilisé par certains champignons. Les sidérophores fongiques forment en effet avec le fer $\left(\mathrm{Fe}^{+++}\right)$un chélate dont la constante de stabilité est inférieure à celle des complexes ferripyoverdines. Ainsi les fusarinines, sidérophores produits par les Fusarium spp (Emery, 1965; Lemanceau et al, 1986), forment avec le fer $\left(\mathrm{Fe}^{+++}\right)$un complexe dont la constante de stabilité est estimée à $10^{29}$ (Scher et Baker, 1982). De ce fait, les Pseudomonas fluorescents sont plus aptes à mobiliser le fer que les Fusarium (Lemanceau, 1988). La croissance de ces champignons en présence de Pseudomonas fluorescents ou de pyoverdine purifiée serait donc réduite du fait de la carence en fer. L'introduction de pyoverdine dans le sol détermine une diminution du taux de germination des chlamydospores de Fusarium (Elad et Baker, 1985) et de la gravité de la fusariose et du piétin (Kloepper et al, 1980b). Sneh et al
(1984) ont, de plus, établi une corrélation entre l'intensité de la synthèse de sidérophores par les Pseudomonas fluorescents in vitro, et leur aptitude à réduire la germination des chlamydospores de Fusarium dans le sol. Meyer et al (1987) ont également mis en évidence, in vitro, la réduction de la croissance d'une souche de Pythium consécutive à des apports croissants de pyoverdine purifiée. L'activité antagoniste exercée par la pyoverdine est effectivement liée à la compétition pour le fer puisqu'elle est annulée lors de l'apport de fer (Kloepper et al, 1980b; Meyer et al, 1987). De plus, la répression de la synthèse de sidérophore, consécutive à l'augmentation de la concentration en fer du milieu, peut s'accompagner de la levée de l'activité antagoniste exercée par différents Pseudomonas fluorescents (Misaghi et al, 1982; Lemanceau et Samson, 1983). D'une façon générale, l'apport de fer disponible pour les champignons pathogènes (Fusarium oxysporum f spp, Gaeumannomyces graminis var triticl) réduit l'intensité de la compétition pour cet élément et aggrave les maladies (Kloepper et al, 1980b; Scher et Baker, 1982; Wong et Baker, 1984; Lemanceau et al, 1988a). À l'inverse, l'activité antagoniste des Pseudomonas est accrue en abaissant la concentration en fer disponible à la suite de l'introduction d'un puissant ligand du fer : l'éthylènediaminedi[(o-hydroxyphényl) acide acétique] (EDDHA) (Scher et Baker, 1982; Van Peer et al, 1990b).

L'activité antagoniste exercée par des Pseudomonas fluorescents à l'encontre de Pseudomonas délétères peut également être associée à la compétition pour le fer (Bakker et al, 1986a). Cependant cette compétition ne semble pas être liée à la plus ou moins grande affinité des pyoverdines pour le fer. Les différences de structure entre pyoverdines ne concernent en effet surtout les acides aminés qui ne participent pas directement à la chélation du fer. Par contre, la plus ou moins grande spécificité du système d'acquisition du complexe ferripyoverdine semble responsable de la compétition pour le fer exercée par certaines souches. Dans l'ensemble, ce système d'acquisition est très spécifique (Hohnadel et Meyer, 1988). II repose sur la synthèse de protéines membranaires (Bitter et al, 1991). Contrairement aux autres souches de Pseudomonas fluorescents, les protéines membranaires des $P$ seudomonas fluorescents antagonistes seraient peu spécifiques. Ces Pseudomonas antagonistes seraient donc capables d'utiliser les complexes ferripyoverdines produits par d'autres 
souches de Pseudomonas. À l'inverse, leurs pyoverdines associées au fer ne seraient reconnues que par un nombre limité de souches de Pseudomonas. Cette hypothèse a été formulée par les chercheurs hollandais à la suite de travaux portant sur 2 souches de Pseudomonas. L'une (WCS358) est antagoniste de l'autre (WCS374) sur milieu carencé en fer (Bakker et al, 1986a). Grâce à l'utilisation de mutants Tn5 non producteurs de sidérophores, de Weger et al (1988) ont montré que la souche antagoniste (WCS358) est capable d'utiliser sa propre pseudobactine ainsi que celle de la souche sensible (WCS374), alors que la souche sensible ne peut utiliser que sa propre pseudobactine. D'une façon plus générale, seul $1 \%$ des souches de Pseudomonas fluorescents isolées de la rhizosphère de pomme de terre serait capable de reconnaître la pseudobactine 358 (Bakker et Bakker, in: Bakker et al, 1990). Le même type de démonstration a été établi par Buyer et Leong (1986).

L'utilisation de mutants ayant perdu l'aptitude à synthétiser des sidérophores (Sid-) a permis de montrer que l'activité bénéfique de certaines souches de Pseudomonas fluorescents est bien due à la synthèse de pyoverdines (Bakker et al, 1986a, 1987; Becker et Cook, 1988; Loper, 1988). Ainsi ces différents auteurs ont établi que les mutants Sid-, bien qu'ils colonisent la racine avec la même efficacité que la souche sauvage, ne déterminent pas les effets bénéfiques enregistrés avec la souche sauvage. II est donc possible d'associer directement ces effets bénéfiques à l'aptitude des Pseudomonas fluorescents à synthétiser des sidérophores in situ.

Pour être complète, la démonstration du rôle des sidérophores dans l'activité antagoniste de certains Pseudomonas fluorescents PGPR nécessite la mise en évidence de leur synthèse dans le sol et la rhizosphère. Compte tenu des conditions physico-chimiques du sol, $\mathrm{pH}$ en particulier, Misaghi et al (1988) mettent en effet en doute la capacité des Pseudomonas fluorescents à synthétiser des sidérophores à un niveau suffisamment élevé pour modifier les interactions microbiennes. La présence de sidérophores microbiens dans le sol a cependant été mise en évidence de façon indirecte. Ceci a été possible grâce à l'utilisation de microrganismes auxotrophes ne synthétisant pas de sidérophores ( $\mathrm{PO}$ well et al, 1980, 1983; Akers, 1983; Reid et al, 1984; Bossier et Vestraete, 1986). II a, en particulier, été montré que la concentration de sidérophores est plus élevée dans la rhizosphère que dans le sol. Plus récemment, Bakker et al (1990) ont démontré que la synthèse de pseudobactine a effectivement lieu dans la rhizosphère de pomme de terre. La colonisation des racines de pomme de terre par des mutants Tn5 Sid- n'est en effet possible que lorsque ces souches sont co-inoculées avec les souches sauvages dont elles peuvent utiliser les ferripseudobactines. L'obtention récente d'anticorps monoclonaux antiferripseudobactine par Buyer et al (1990) devrait permettre la mise en évidence directe de la production de pseudobactine dans la rhizosphère.

La compétition pour le fer n'est cependant pas le seul mode d'action des Pseudomonas. Même lorsque la synthèse de sidérophores est réprimée à la suite de l'enrichissement en fer du milieu de culture, certaines souches de Pseudomonas fluorescents continuent à exercer leur activité antagoniste à l'encontre de divers microrganismes (Lemanceau et Samson, 1983; Weller et al, 1988). L'association entre l'enrichissement du milieu de culture en fer, la répression de la synthèse de sidérophores et la suppression de l'activité antagoniste de Pseudomonas spp fluorescents ne démontre pas nécessairement que la compétition pour le fer est le seul mode d'action antagoniste (Thomashow et Weller, 1990). En effet, la synthèse de certains antibiotiques, tout comme la synthèse de sidérophores, est régulée par la concentration en fer du milieu. Ceci a été démontré pour la souche de Pseudomonas fluorescent N2 130 antagoniste de Pythium ultimum (Gill et Warren, 1988) et pour la souche 2-79 antagoniste de Gaeumannomyces graminis var tritici (Hamdan et al, 1988).

\section{Antibiose}

L'importance de l'antibiose dans les interactions microbiennes responsables de la protection biologique contre les maladies a fait l'objet d'une récente synthèse bibliographique (Fravel, 1988).

L'antibiose exercée par certains Pseudomonas spp fluorescents a d'abord été mise en évidence in vitro. Alnsi Lindberg (1981) a établi le spectre d'activité d'un antibiotique, la tropolone, synthétisé par une souche de Pseudomonas. Cet antibiotique manifeste des propriétés antagonistes à l'encontre de différents champignons: Alternaria, Cladosporium, Diplodia, Fusarium, Helminthosporium, Pyricularia, Pythium, Rhizoctonia. Howell et Stipanovic $(1979,1980)$ ont caractérisé 2 antibiotiques : la pyolutéorine et la pyrrolnitrine synthétisés par la souche Pf5 
de Pseudomonas fluorescens. Ces antibiotiques ont respectivement inhibé la croissance, in vitro, de Pythium ultimum et de Rhizoctonia solani. Ces auteurs ont ensuite montré que la souche bactérienne protège les plantes de coton contre ces pathogènes de manière analogue à celle des antibiotiques purifiés. Ils en concluent que la protection des plantes assurée par cette souche de Pseudomonas est liée à la synthèse de ces antibiotiques.

L'utilisation de mutants dont les gènes responsables de la synthèse d'antibiotique ont subi une délétion permet d'associer de façon plus directe la protection biologique à l'aptitude à produire l'antibiotique. C'est dans ce but que Kraus et Loper (1990) ont obtenu, par insertion du transposon Tn5, des mutants de la souche Pf5 ayant perdu l'aptitude à synthétiser l'un ou les 2 antibiotiques produits par la souche sauvage. De même, Gutterson et al $(1986,1988)$ ont mis en évidence l'effet antagoniste d'un antibiotique, synthétisé par la souche de Pseudomonas fluorescent HV37a, à l'encontre de Pythium ultimum. Puis Howie et Suslow (1986) ont montré qu'un mutant ne produisant pas cet antibiotique s'est révélé significativement moins apte à protéger le coton contre Pythium ultimum que la souche sauvage. Le même type de démonstration a été établi par Colyer et Mount (1984) pour expliquer la protection assurée par une souche de Pseudomonas putida contre Erwinia carotovora.

Le rôle de 3 autres composés (acide phénazine-1-carboxylique, 2-4 diacétylphloroglucinol, acide cyanhydrique) a été établi selon la même démarche expérimentale. Elle consiste à mettre en évidence successivement : la production in vitro du composé moins bonne que celle assurée par la souche sauvage, son efficacité in vitro à l'encontre du pathogène, la protection contre la maladie assurée par le mutant non producteur du composé moins bonne que celle assurée par la souche sauvage. Thomashow et Weller (1988) ont ainsi démontré que l'acide phénazine1-carboxylique, synthétisé par la souche de Pseudomonas fluorescent 2-79, est en partie responsable de son activité antagoniste à l'encontre de Gaeumannomyces graminis var tritici. Cet antibiotique caractérisé in vitro par Gurusiddaiah et al (1986), produit également par d'autres souches de Pseudomonas (Haynes et al, 1956; Kanner et al, 1978; Flaishman et al, $1990)$ est efficace contre différents champignons (Brisbane et al, 1989). De même, Keel et al $(1990,1991)$ ont démontré que le 2-4 diacétylphloroglucinol synthétisé par la souche de Pseu- domonas $\mathrm{CHAO}$ est en partie responsable de la protection du blé contre Gaeumannomyces graminis var tritici et du tabac contre Thielaviopsis basicola. Ce composé est extrêmement efficace in vitro contre Gaeumannomyces graminis var tritici (Keel et al, 1991). Enfin, Voisard et al (1989) ont démontré que la production d'acide cyanhydrique est également impliquée dans la protection du tabac et du blé assurée par la souche CHAO.

Bien que Thielaviopsis basicola soit sensible in vitro à l'acide cyanhydrique, la souche $\mathrm{CHAO}$ ne réduit pas de façon significative la densité de ce champignon dans le sol (Ahl et al, 1986). Selon ces auteurs, elle pourrait cependant être responsable d'une réduction de l'activité du champignon dans la rhizosphère. Les exsudats racinaires contiennent en effet de la glycine (Rovira et Darvey, 1971) connue pour être un précurseur de la synthèse bactérienne d'acide cyanhydrique (Voisard et al, 1989).

La démonstration du rôle de ces 3 composés a été confortée par l'utilisation de mutants pour lesquels la synthèse de ces produits a été rétablie grâce à leur complémentation avec le cosmide correspondant. Cette complémentation s'est en effet accompagnée de la restauration de l'efficacité de la souche bactérienne à protéger les plantes (Thomashow et Weller, 1988; Voisard et al, 1989; Keel et al, 1990, 1991).

Enfin des techniques de biologie moléculaire ont également permis de stimuler la production de 2-4 diacétylphloroglucinol par la souche CHAO ou même d'induire la production d'acide cyanhydrique (Voisard et al, 1989) et de phénazine (Thomashow, 1991), de 2-4 diacétylphloroglucinol et de pyolutéorine (Maurhofer et al, 1991) dans différentes souches de Pseudomonas.

La stimulation de la production d'acide cyanhydrique et de phénazine a amélioré l'efficacité des bactéries à réduire la gravité de la maladie (Voisard et al, 1989; Thomashow, 1991). Par contre, selon la plante hôte, la stimulation de la synthèse de 2-4 diacétylphloroglucinol et de pyolutéorine par la souche $\mathrm{CHAO}$ a déterminé soit une augmentation soit une réduction de la protection contre la maladie pouvant même s'accompagner d'un effet délétère sur la croissance de la plante bactérisée (Maurhofer et al, 1991).

Comme précédemment pour les sidérophores, la démonstration du rôle des antibiotiques, pour être entièrement satisfaisante, nécessite la mise en évidence de leur synthèse in situ. Or jusqu'à 
un passé récent, il n'existait pas de preuve directe de la synthèse et du maintien des antibiotiques à un niveau suffisant, dans le sol, pour permettre l'expression de leur activité biologique (Williams et Wickers, 1986). Mais récemment, la synthèse de l'acide phénazine-1-carboxylique et du 2-4 diacétylphloroglucinol par les souches 279 et CHAO respectivement a été mise en évidence dans le sol (Defago et al, 1990; Thomashow et al, 1990). La concentration de ces antibiotiques a été mesurée. L'efficacité des souches bactériennes étudiées a pu être directement corrélée à la présence des antibiotiques dans les extraits de racines, la rhizosphère et le sol.

\section{Modification du métabolisme et de la physiologie de la plante}

Au cours des années 1960 et 1970, les chercheurs se sont surtout intéressés aux effets directs des rhizobactéries sur la croissance des plantes. Puis, pendant les années 1980, leur attention a surtout été retenue par l'étude de l'activité antagoniste des Pseudomonas spp fluorescents à l'encontre des microrganismes pathogènes. Mais des publications récentes, traitant de l'alimentation minérale et de l'induction de résistance de la plante, attestent d'un regain d'intérêt en faveur des interactions directes entre la plante et les rhizobactéries.

\section{Amélioration de l'alimentation minérale de la plante}

L'amélioration de l'alimentation minérale de la plante en phosphore a été la première hypothèse proposée pour expliquer l'effet bénéfique enregistré à la suite de la bactérisation de plantes (Gerretsen, 1948). Les espèces, Bacillus megaterium var phosphaticum et Pseudomonas spp fluorescents, augmenteraient la concentration en phosphore soluble soit par minéralisation des phosphates organiques, grâce à des phosphatases, soit par solubilisation des phosphates inorganiques, sous l'effet d'acides (Krasilnikov, 1961). Ce mode d'action a fait l'objet de nombreuses controverses. Ainsi Mishutin et Naumova (1962) calculèrent que la quantité de phosphates solubilisés sous l'action des bactéries est négligeable par rapport à l'augmentation de rendement observée au champ. Benians et Barber (1974) ont même montré que des plantes, cultivées en sol stérile, prélèvent plus de phosphates et présentent un poids supérieur à celles culti- vées en sol non stérile.

Rovira (1972) suggère, pour sa part, que l'amélioration de l'absorption de phosphates par la plante, grâce à l'activité de certains microrganismes, serait lié à la modification de la croissance et de la longévité du système racinaire.

Plus récemment, Lifshitz et al (1987) ont mis en évidence qu'une souche de Pseudomonas putida (G12-2) stimule la croissance du colza en absence de microrganisme pathogène. Cette souche améliore le prélèvement de phosphore marqué ( $\left.{ }^{32} \mathrm{P}\right)$ par les plantes. II existe une corrélation positive entre la longueur des racines et leur teneur en ${ }^{32} \mathrm{P}$. Les auteurs associent donc l'effet bénéfique de la souche G12-2 à une meilleure alimentation de la plante en phosphore.

Lifshitz et al (1986) ont également isolé, de la rhizosphère de colza, des Pseudomonas spp fixateurs d'azote. Cependant, leur rôle positif n'a pas pu être démontré.

Enfin, les sidérophores microbiens et en particulier ceux des Pseudomonas fluorescents peuvent influencer directement l'alimentation de la plante en fer (Crowley et al, 1987). Ainsi le fer chélaté par les sidérophores peut être utilisé par les graminées. Powell et al (1982) ont par exemple mis en évidence, grâce à l'utilisation de $55 \mathrm{Fe}$, que l'avoine peut assimiler le fer lié aux sidérophores. De même, Duss et al (1986) ont observé que la tomate n'absorbe le fer de façon efficace que si elle est cultivée en présence de bactéries. Cependant tous les sidérophores n'améliorent pas l'alimentation en fer des plantes. Ainsi l'assimilation du fer par le maïs et le pois a été réduite en présence d'une pseudobactine. Cette réduction s'est accompagnée d'une diminution de la concentration en fer de la chlorophylle (Becker et al, 1985).

\section{Production microbienne de substances de croissance}

La production de substances de croissance par les Pseudomonas fluorescents a été fréquemment mise en évidence in vitro (Brown, 1974; Lynch, 1976). Ces substances peuvent être absorbées par les racines. Ainsi Libbert et al (1969) ont montré que des auxines produites par des microrganismes telluriques pouvaient être assimilées par différentes plantes (maïs, pois, concombre).

Différents auteurs ont mis en relation l'aptitude de souches microbiennes à produire des 
substances de croissance in vitro et leur aptitude à modifier, in vivo, la morphologie des plantes de manière analogue aux substances de croissance concernées. Ils en concluent que la stimulation de croissance des plantes bactérisées est due à la synthèse microbienne de substances de croissance (Brown, 1974).

La synthèse de ces substances n'a cependant pas été mise en évidence in situ. De plus, Rivière (1966) puis Strzelczyk et al (1973) signalent que les bactéries capables de dégrader l'acide indole acétique (AIA) sont au moins aussi fréquentes que celles capables de synthétiser cet acide. L'importance relative de ces 2 types de bactéries semble dépendre du stade de développement de la plante qui influence la composition des exsudats racinaires (Rivière, 1966; Rovira, 1972). Enfin les différences enregistrées entre plantes traitées avec bactéries ou substances de croissance et plantes témoin, ne sont significatives que sur jeunes plantes; elles disparaissent en cours de culture (Jackson et al, 1964; Ecklund, 1970; Brown, 1974).

Plus récemment, Loper et Schroth (1986b) ont même montré que l'effet délétère de certains Pseudomonas fluorescents pourrait être associé à l'intensité de la synthèse de AIA in vitro. Ainsi, ces auteurs ont établi une corrélation entre la concentration d'AIA produite in vitro et la réduction de l'élongation racinaire après bactérisation. Cette corrélation a été confirmée en comparant l'effet biologique de l'inoculation d'une souche de Pseudomonas syringae pv savastanoi productrice d'AlA et de son mutant non producteur d'AIA. La souche sauvage provoque une réduction de la croissance racinaire alors que le mutant demeure sans effet.

\section{Induction de résistance de la plante}

Des travaux récents portant sur des modèles d'étude différents ont mis en évidence la plus grande résistance naturelle des plantes bactérisées par certaines souches de Pseudomonas.

Ainsi, la souche bactérienne $\mathrm{CHAO}$ provoque une augmentation du chevelu racinaire et la résistance naturelle au Thielaviopsis basicola des plantes de tabac bactérisées (Voisard et al, 1989). Ces auteurs associent ces 2 effets bénéfiques à la synthèse bactérienne d'acide cyanhydrique $(\mathrm{HCN})$ grâce aux techniques de génie génétique suivantes:

- obtention d'un mutant non producteur de $\mathrm{HCN}$ issu de la souche $\mathrm{CHAO}$,

- complémentation de ce mutant avec les gènes responsables de la synthèse de $\mathrm{HCN}$,

- introduction de ces gènes dans une souche initialement non productrice de $\mathrm{HCN}$.

Defago et al (1990) suggèrent donc que la production de HCN par la souche CHAO provoquerait sur la plante un stress auquel elle réagirait par une augmentation de son système racinaire et de sa résistance naturelle.

Pour Anderson et Guerra (1985), l'augmentation de la résistance des plantes de haricot au Fusarium solani grâce à l'inoculation d'une souche de Pseudomonas putida serait liée à leur plus grande teneur en lignine.

L'induction de résistance de l'œillet à la fusariose vasculaire par la souche de Pseudomonas WCS417r a été clairement établie par Van Peer et al (1991). En effet, le rôle de l'antagonisme direct, entre la souche de Pseudomonas et celle de Fusarium pathogène, dans la protection biologique a pu être exclu grâce à des inoculations séparées dans l'espace : inoculation racinaire pour la souche bactérienne, inoculation dans la tige pour le Fusarium. De plus, l'induction de résistance de plantes ainsi inoculées est associée à une augmentation de la synthèse de phytoalexines comparées à celle des plantes témoins inoculées avec le Fusarium pathogène. L'induction de résistance des plantes bactérisées serait due aux lipopolysaccharides de la souche WCS417r. En effet, l'apport à la plante de lipopolysaccharides partiellement purifiés issus de la souche WCS417r détermine un effet bénéfique analogue à celui la souche bactérienne ellemême (Van Peer et al, résultats non publiés).

Enfin, suivant un dispositif expérimental inspiré de celui décrit par Kuc et al (1975), Wei et al (1991) ont également mis en évidence l'aptitude d'une souche de Pseudomonas fluorescent à induire la résistance de plantes de concombre à Colletotrichum lagenarium.

\section{CONDITIONS NÉCESSAIRES À L'EXPRESSION DES EFFETS BÉNÉFIQUES}

La connaissance, même partielle, des mécanismes responsables des effets bénéfiques des $P$ seudomonas spp fluorescents permet de préciser les conditions favorables à leur expression. Ces conditions sont liées aux souches de Pseudomonas utilisées mais également à l'environnement dans lequel l'inoculation bactérienne est pratiquée. 


\section{Caracteristiques des souches de Pseudomonas}

Les effets bénéfiques de la bactérisation résultent à la fois des activités spécifiques des bactéries et de leur densité dans la rhizosphère de la plante hôte. Ainsi l'efficacité des souches de Pseudomonas fluorescents utilisées dépend de leur aptitude à produire certains métabolites. Comme décrit précédemment, les métabolites responsables d'activités spécifiques intéressantes sont variés : sidérophores, antibiotiques, substances de croissance, lipopolysaccharides, etc.

La sélection de souches de Pseudomonas fluorescents performantes ne doit cependant pas se limiter à ces seules activités qui seraient de peu d'utilité si les bactéries n'étaient pas aptes à se maintenir et à coloniser le système racinaire de la plante hôte.

La compétence rhizosphérique des Pseudomonas fluorescents varie d'une souche à l'autre. Cette compétence définit l'aptitude d'une souche à se distribuer le long des racines de la plante hôte, à se multiplier et survivre pendant plusieurs semaines en présence de la microflore rhizosphérique indigène (Bahme et Schroth, 1987; Weller, 1988).

Les caractéristiques bactériennes qui conditionnent la bonne compétence rhizosphérique des souches de Pseudomonas sont relativement méconnues. Ces caractéristiques semblent liées à l'aptitude des souches à :

- à s'attacher à la racine;

- se déplacer vers et le long de la racine;

- entrer en compétition de façon efficace avec la microflore résidente.

En effet la colonisation racinaire s'effectue en 2 temps. Les bactéries s'attachent d'abord à la racine et sont donc distribuées de façon passive. Puis elles se multiplient et colonisent de façon active la rhizosphère (Howie et al, 1987).

L'attachement des bactéries à la racine résulte d'interactions physico-chimiques et biologiques entre les bactéries et la racine. Ainsi l'adhésion des bactéries à la racine serait d'autant plus efficace que la surface de la cellule bactérienne est hydrophobe (Van Loosdrecht et al, 1987). Cette adhésion est également conditionnée par des phénomènes électrostatiques mettant en cause en particulier les charges de surface de la cellule bactérienne (James et al, 1985; Dickson et Koohmaraie, 1989). Cependant, les travaux de Weger et al (1989a) tendraient à minimiser l'importance de la composante physico-chimique de l'adhésion. L'adhésion des Pseudomonas à la racine dépend plutôt de leur aptitude à s'agglutiner avec des glycoprotéines, appelées agglutinines, produites par la plante (Jasalavich et Anderson, 1981; Anderson, 1983). Ainsi la perte de cette aptitude, après mutation, chez une souche de Pseudomonas putida, s'est accompagnée d'une réduction de sa colonisation racinaire (Anderson et al, 1988). Le phénomène d'agglutination est relativement spécifique. Les bactéries rhizosphériques s'agglutinent plus fréquemment avec des agglutinines racinaires que les bactéries non rhizosphériques (Chao et al, 1988). De plus, les souches isolées de la rhizosphère de blé et de graminées sont plus souvent agglutinées avec des agglutinines de blé que ne le sont les isolats issus d'autres espèces végétales. Cette spécificité pourrait être associée à la nature des lipopolysaccharides et des protéines membranaires et varierait selon l'espèce végétale dont elles sont isolées (Glandorf et al, 1991).

Les lipopolysaccharides bactériens jouent effectivement un rôle déterminant dans la colonisation racinaire. Ainsi de Weger et al (1989b) ont montré que la suppression de la chaine 0 antigénique des lipopolysaccharides, sous l'action d'un bactériophage, s'accompagne d'une moins bonne colonisation de la partie inférieure du système racinaire. La chaîne $O$-antigénique ne semble cependant pas impliquée dans l'adhésion bactérienne à la racine (de Weger et al, 1989a). II a, par ailleurs, été établi que les lipopolysaccharides contribuent à protéger la cellule bactérienne de la dessication (Fett et al, 1989).

Les pili et fimbriae présents sur certaines bactéries sont également responsables de l'adhésion des bactéries à la racine (Korhonen et al, 1983). Ainsi, l'attachement de la souche 2-79 est corrélé à la présence de pili (Vesper, 1987). La souche WCS358 présente également des pili (de Weger, 1988). II est cependant difficile d'évaluer l'importance exacte des pili dans un environnement aussi complexe que celui de la rhizosphère (Bakker et al, 1991) : leur présence dépend en effet des conditions du milieu (Van Verseveld et al, 1985).

L'attraction des Pseudomonas vers la racine sous l'effet du chimiotactisme exercé par les exsudats et le déplacement de ces bactéries dans la rhizosphère sont également des composantes de la colonisation racinaire. À nouveau, leur importance est sujette à discussion. En effet, même si Scher et al (1985 et 1988) ont mis en 
évidence le chimiotactisme exercé par les exsudats de graines de soja à l'égard de Pseudomonas fluorescents, cette attraction n'a pas pu être corrélée à une meilleure colonisation racinaire. Le rôle des flagelles bactériens dans la colonisation racinaire semble différer selon les souches et les conditions de croissance. Ainsi, de Weger et al (1987) ont démontré que la présence de flagelles permet, à la souche WCS374, de coloniser les racines profondes de façon efficace. Alors que ni Howie et al (1987), ni Scher et al (1988) n'ont observé de différence entre la colonisation de souches flagellées et de leurs mutants non flagellés.

Le maintien et le développement de la souche bactérienne introduite sont conditionnés par la capacité d'accueil de la rhizosphère. Certaines souches bactériennes présentent une aptitude compétitrice supérieure à d'autres. Les caractéristiques microbiennes responsables de cet avantage sont relativement méconnues. De façon assez surprenante, ces caractéristiques ne semblent liées ni à la production de sidérophores ni à la production d'antibiotiques; les mutants non producteurs de ces métabolites paraissent en effet coloniser la rhizosphère aussi bien que les souches sauvages (Bakker et al, 1986a; 1987; Keel et al, 1989; Thomashow et Weller, 1988). Cependant, lors d'essais de longue durée, Thomashow (1991) a récemment mis en évidence la meilleure survie de la souche sauvage comparée à celle de mutants non producteurs d'antibiotique. De même, Bakker et al (1991) ont clairement établi que l'aptitude d'une souche de Pseudomonas à utiliser le sidérophore produit par une autre souche lui confère un avantage sélectif. Ainsi l'introduction des gènes responsables de la synthèse des protéines membranaires réceptrices de la pseudobactine 358 , dans le génome de la souche WCS374 améliore significativement la survie de cette souche lorsqu'elle est inoculée avec la souche WCS358.

La colonisation des Pseudomonas est également influencée par leur localisation au niveau de la racine. Ainsi les bactéries endophytes ou endorhizosphériques (Mclnroy et Kloepper, 1991; Van Peer et al, 1990a) seraient moins sujettes à la compétition que celles situées à l'extérieur de la racine. En effet, la densité des populations bactériennes, et donc l'intensité de la compétition, sont plus réduites à l'intérieur qu'à l'extérieur de la racine. L'aptitude de certaines souches à coloniser l'endorhizosphère est corrélée à leur aptitude à s'agglutiner sous l'action d'agglutinines racinaires. Ces souches se caractérisent également par la nature de leurs lipopolysaccharides et de leurs protéines membranaires (Van Peer et al, 1990a).

\section{Environnement}

Pour déterminer les effets bénéfiques décrits dans le chapitre Présentation des effets bénéfiques, les souches de Pseudomonas doivent rencontrer un environnement favorable à l'expression de leurs activités spécifiques intéressantes et à leur survie.

Ainsi, Rosenweig et Stotzky (1979 et 1980) ont montré que l'antagonisme exercé dans le sol par des bactéries à l'encontre de champignons est influencé par les caractéristiques physicochimiques du sol. L'exemple le mieux documenté dans ce domaine est celui décrit par Defago et al (1990). Stuz et al (1989) ont en effet établi que la souche $\mathrm{CHAO}$ se révèle être un agent de lutte biologique efficace uniquement si elle est introduite dans un sol ou un substrat comportant une argile particulière : la vermiculite. Cette argile semble présenter une concentration en fer disponible suffisamment élevée pour permettre la synthèse bactérienne d'acide cyanhydrique (Keel et al, 1989). Or, comme décrit ci-dessus, ce métabolite est en partie responsable de l'effet bénéfique de la souche CHAO. Par contre, lorsque la plante inoculée est cultivée dans un sol présentant une argile pauvre en fer (illite), cette souche demeure sans effet à moins que le sol ne soit amendé en fer (Keel et al, 1989). À l'inverse, Van Peer et al (1990b) ont montré que l'efficacité de la souche WSC417r, utilisée pour lutter contre la fusariose de l'œillet, est significativement améliorée lorsque la disponibilité en fer est réduite par l'utilisation de EDDHA dans la solution nutritive. L'efficacité de cette souche est en effet due en partie à la synthèse de sidérophore.

Les caractéristiques biologiques du sol sont également déterminantes. En absence de microrganisme pathogène, une souche de Pseudomonas dont le mode d'action est l'antagonisme microbien ne modifiera pas la croissance de la plante inoculée. Ainsi, la bactérisation de tubercules de pomme de terre cultivés dans un sol présentant une microflore délétère réduite avec la souche WCS358 ne s'accompagne pas d'une augmentation significative du rendement de la culture (Bakker et al, 1986a). Il faut donc que le facteur limitant sur lequel agit la bactérie soit effectif pour que l'effet de la bactérie soit visible. 
Une souche de Pseudomonas demeure également sans effet lorsque la réduction de rendement des plantes témoins est due à un microrganisme pathogène insensible à l'activité antagoniste bactérienne (Weller, 1988).

L'espèce végétale à laquelle appartient la plante hôte joue probablement un rôle non négligeable sur l'activité des Pseudomonas. II est en effet admis que le métabolisme des Pseudomonas est influencé par les nutriments mis à leur disposition (Leisinger et Margraff, 1979). La production d'acide cyanhydrique requiert par exemple la présence de glycine (Knowles, 1976). La nature des métabolites bactériens pourrait donc être influencée par la composition des exsudats racinaires. De plus, l'intensité du métabolisme microbien est conditionnée par la quantité de nutriments disponibles. Ainsi la prodution de sidérophores est plus élevée lorsque la concentration en carbone du milieu est plus importante (Elad et Baker, 1985).

La plus ou moins bonne survie d'une souche de Pseudomonas dans la rhizosphère dépend également du sol et de la plante hôte (Atkinson et al, 1975; Weller, 1986; Bahme et Schroth, 1987). Différents auteurs ont, par exemple, montré que l'humidité du sol est un facteur très important (Dupler et Baker, 1984; Howie et al, 1987). Selon la texture du sol, la meilleure colonisation racinaire a lieu à des valeurs de potentiel hydriques comprises entre $-0,01$ et $-1,4$ bar (Howie et al, 1987; Liddel et Parke, 1989). Bahme et Schroth (1987) ont également montré que la colonisation bactérienne est influencée par la texture du sol. Ainsi les argiles contribueraient à protéger les bactéries des stress hydriques (Dupler et Baker, 1984). La technique d'irrigation joue aussi un rôle déterminant. La percolation de l'eau contribue à améliorer la distribution des bactéries le long de la racine et à augmenter leur densité à l'extrémité des racines (Chao et al, 1986; Parke et al, 1986). La température affecte également la croissance bactérienne et la production de sidérophores in vitro ainsi que la colonisation racinaire (Loper et al, 1985; Digat et Mattar, 1990). Ces derniers auteurs ont montré que la sensibilité de différentes souches de Pseudomonas à la température du milieu environnant dépend de leur origine géographique.

Les caractéristiques microbiologiques du sol influencent directement la survie de la souche de Pseudomonas inoculée. Cette survie est d'autant meilleure que la biomasse microbienne est limitée (Compeau et al, 1988; Davies et Whitbread, 1989; Morel et al, 1989) et que la quantité de nutriments est importante (Wessendorf et Lingens, 1989).

La plante hôte conditionne également l'efficacité de la colonisation racinaire. Ainsi, comme décrit précédemment, les travaux portant sur l'agglutination tendraient à montrer qu'il existe une certaine spécificité entre la bactérie et la plante hôte (Glandorf et al, 1991).

\section{CONCLUSIONS}

Les premières publications issues de l'université de Berkeley relatives aux «Plant Growth Promoting Rhizobacteria" ont suscité intérêt et enthousiasme au sein de la communauté scientifique des microbiologistes et pathologistes du sol.

Effectivement, le nombre de communications écrites et orales relatives à ces bactéries ne cesse de s'accroître. Mais en dépit de l'importance du travail fourni, la seule application commerciale qui ait vu le jour ne s'est pas poursuivie. II s'agissait de l'utilisation d'une souche de Pseudomonas fluorescens pour protéger les plantes de coton contre la fonte du semis (Currier et al, 1988).

Outre les problèmes d'homologation inhérents à l'emploi d'organismes vivants en agriculture, cet état de fait est principalement dû au manque de reproductibilité des effets bénéfiques de la bactérisation (Weller, 1988).

Une grande partie de l'effort de recherche a consisté à évaluer, de façon empirique, l'effet bénéfique de souches de Pseudomonas éventuellement présélectionnées in vitro. Or, selon les conditions d'utilisation, ces souches peuvent se révéler efficaces lors d'un essai et inefficaces lors du suivant...

$\mathrm{Ce}$ problème majeur a incité quelques équipes à étudier de façon approfondie les mécanismes responsables des effets bénéfiques enregistrés. Ainsi, des progrès certains ont été accomplis dans la compréhension de ces mécanismes grâce à l'utilisation de techniques de biologie moléculaire, reposant en particulier sur I'utilisation de mutants (Defago et Haas, 1990). II apparaît maintenant clairement que plusieurs mécanismes peuvent être impliqués. Ces mécanismes reposent sur la production de différents métabolites bactériens: sidérophores, antibiotiques, substances de croissance, lipopolysaccharides, etc.

La meilleure connaissance des mécanismes responsables des effets bénéfiques autorise maintenant à envisager d'améliorer l'efficacité 
des souches bactériennes employées. Les techniques de génie génétique peuvent ainsi permettre d'amplifier la synthèse de métabolites intéressants. II existe déjà 2 exemples de telle modification : I'un concerne la synthèse de 2,4diacétylphloroglucinol et de pyolutéorine (Maurhofer et al, 1991), l'autre la synthèse de phénazine (Pierson et Thomashow, 1991). L'inactivation des gènes responsables de la répression de la synthèse de sidérophores a permis d'obtenir 2 souches, issues de la souche WCS358, dont la synthèse de pseudobactine n'est plus dépendante de la concentration en fer du milieu (Ottevanger et al, résultats non publiés).

II faut cependant se garder de généraliser l'effet bénéfique d'un métabolite à l'ensemble des souches de Pseudomonas et des modèles d'étude. Ainsi, l'effet bénéfique des sidérophores, démontré pour de nombreuses souches: B10, A12, WCS358, etc (Kloepper et al, 1980c; Scher et Baker, 1982; Bakker et al, 1987), semble limité pour la souche 2-79 (Hamdam et al, 1988) voire inexistant pour la souche CHAO (Keel et al, 1989). De plus, selon la plante hôte utilisée et l'intensité de leur synthèse, certains métabolites peuvent se révéler bénéfiques ou néfastes. Ainsi la synthèse d'acide cyanhydrique par la souche CHAO est responsable, en partie au moins, de la protection du tabac et du blé respectivement contre Thielaviopsis basicola et Gaeumannomyces graminis var tritici (Voisard et al, 1989; Defago et al, 1990) alors que cette synthèse est à l'origine de l'effet délétère d'autres souches de Pseudomonas (Bakker et Schippers, 1987).

Compte tenu de la diversité et de la complexité des interactions entre la microflore, le sol et la plante, plus les mécanismes mis en œuvre seront variés, plus l'efficacité de l'inoculation microbienne sera assurée. Pour atteindre cet objectif, 2 stratégies peuvent être poursuivies : l'une consiste à utiliser une souche microbienne apte à synthétiser différents métabolites intéressants, l'autre consiste à utiliser en association des souches qui déterminent des mécanismes complémentaires.

Ainsi les souches CHAO, 2-79 et WCS417r synthétisent des métabolites variés responsables de mécanismes divers. II est également possible d'augmenter le nombre de métabolites différents produits par une même souche en introduisant dans son génome des gènes issus d'une autre souche. Deux applications de cette technique ont été décrites : l'une concerne l'introduction des gènes responsables de la synthèse de HCN issus de la souche CHAO (Voisard et al,
1989), l'autre concerne l'introduction des gènes responsables de la synthèse d'une phénazine (Thomashow, 1991). Ce type de manipulation n'est possible que si le nombre de gènes impliqués est réduit. Ce n'est pas le cas pour la synthèse de sidérophores (Marugg et al, 1985). Par contre, les gènes responsables de la synthèse des protéines membranaires réceptrices du complexe ferripseudobactine, issus de la souche WCS358, ont pu être clônés (Marugg et al, 1989) puis transférés à la souche WCS374 lui conférant ainsi un avantage sélectif (Leong et al, 1991).

La co-inoculation de microrganismes différents permet également de diversifier les mécanismes responsables d'effets bénéfiques. Ainsi Weller et Cook (1983) puis Pierson et Weller (1990) ont montré que l'inoculation de 2 souches de Pseudomonas spp fluorescents permet de protéger le blé contre le piétin significativement mieux que l'inoculation d'une seule souche bactérienne. De même, la protection contre la fusariose de la tomate, assurée par l'association d'une souche de Fusarium non pathogène et d'une souche de Pseudomonas fluorescent, est plus efficace que la seule inoculation de l'un des 2 microrganismes antagonistes (Lemanceau et Alabouvette, 1991). Lors d'essais complémentaires, Lemanceau et al (résultats non publiés) ont montré que la plus grande efficacité de la co-inoculation de la souche de Fusarium non pathogène Fo47 avec la souche de Pseudomonas WCS358 est liée à la complémentarité des mécanismes : compétition pour le carbone pour la souche Fo47 et compétition pour le fer pour la souche WCS358.

$\mathrm{Si}$ des progrès importants ont été réalisés dans la connaissance et la gestion des mécanismes bénéfiques de l'inoculation microbienne, la compréhension des facteurs responsables de la compétence rhizosphérique d'une souche de Pseudomonas demeure par contre très fragmentaire. Pourtant, quelle que soit la diversité des métabolites synthétisés et quelle que soit l'intensité de cette synthèse, les effets bénéfiques de la bactérisation ne se manifesteront que si la densité bactérienne est suffisamment élevée. II semble que l'adhésion des bactéries à la racine, en leur conférant un avantage sélectif, constitue une composante importante de la colonisation racinaire. Par ailleurs, l'utilisation de souches aptes à coloniser l'endorhizosphère de la plante pourrait permettre de maintenir la densité des bactéries pendant une période plus longue. Enfin, la colonisation racinaire est probablement aussi influencée de façon importante par la formulation de l'inoculum (Kloepper et Schroth, 1981a; Paau, 1989; Digat, 1991). 
L'étude des effets bénéfiques des Pseudomonas spp fait appel à des domaines de compétence très divers qui, associés, ont permis de réaliser des progrès substantiels dans la connaissance des mécanismes et des conditions d'expression des effets bénéfiques. II est cependant regrettable de constater que la diversité phénotypique et génotypique des populations naturelles de Pseudomonas spp fluorescents telluriques ait jusqu'à présent peu été prise en compte (Lemanceau et al, 1986). II est en effet possible que la caractérisation de cette diversité permette d'appréhender l'étude de l'adaptation des Pseudomonas fluorescents à la rhizosphère et à la racine de la plante hôte avec de nouvelles hypothèses. En dépit de cette lacune, force est de constater que les progrès, évoqués précédemment, permettent dès maintenant d'améliorer l'efficacité et la reproductibilité des augmentations de rendement des cultures bactérisées.

\section{REMERCIEMENTS}

J'exprime ma gratitude à $R$ Bardin (université Claude Bernard, Lyon I) qui m'a incité à rédiger cette synthèse; C Alabouvette (INRA, Dijon) qui m'a encouragé et conseillé; $P$ Bakker (université d'Utrecht, Pays-Bas) qui a relu le manuscrit.

\section{RÉFÉRENCES}

Ahl P, Voisard C, Defago G (1986) Iron boundsiderophores, cyanic acid, and antibiotics involved in suppression of Thielaviopis basicola by a Pseudomonas fluorescens strain. J Phytopathol 116, 121-134

Akers HA (1983) Multiple hydroxamic acid microbial chelators (siderophores) in soil. Soil Sci 135, 156160

Alten $H$ (von), Lindermann A, Schon Beck F (1991) Increasing VA-mycorrhization with application of rhizosphere bacteria. In: The rhizosphere and plant growth (Kleister DL, Cregan PB, eds) Kluwer Acad Publ, 381

Alabouvette C (1983) La réceptivité des sols aux fusarioses vasculaires. Rôle de la compétition nutritive entre microorganismes. Thèse dr es sci nat, univ Nancy, $158 \mathrm{p}$

Anderson AJ (1983) Isolation from root and shoot surfaces of agglutinins that show specificity for saprophytic pseudomonads. Can J Bot 61, 3438-3443

Anderson AJ, Guerra D (1985) Responses of bean to root colonization with Pseudomonas putida in hydroponic system. Phytopathology 75, 992-995

Anderson AJ, Habibzadegah-Tari P, Tepper CS (1988) Molecular studies on the role of a root agglutinin in adherence and colonization by Pseudomonas putida. Appl Environ Microbio/ 54, 375-380

Atkinson TG, Neal LJJ, Larson RI (1975) Genetic control of the rhizosphere microflora of wheat. $\mathrm{In}$ : Biology and control of soilborne pathogens (GW Bruehl, ed) Am Phytopathol Soc, Saint Paul, MN, 116-122

Bahme JB, Schroth MN (1987) Spatial temporal colonization patterns of rhizobacterium on underground organs of potato. Phytopathology 77, 1093-1100

Baker KF, Cook RJ (1974) Biological control of plant pathogens. A Phytopathol Soc, St Paul, MN, $433 p$

Bakker AW, Schippers B (1987) Microbial cyanide production in the rhizosphere in relation to potato yield reduction and Pseudomonas spp mediated plant growth stimulation. Soil Biol Biochem 19, 451-457

Bakker PAHM, Lammers JG, Bakker AW, Marugg JD, Weisbeek PJ, Schippers B (1986a) The role of siderophores in potato tuber yield increase by Pseudomonas putida in short rotation of potato. Neth J Plant Pathol 92, 249-256

Bakker PAHM, Weisbeek PJ, Schippers B (1986b) The role of siderophore in plant growth stimulation by fluorescent Pseudomonas spp. Meded Fac Landbouw Rijksuniv Gent 51, 1357-1362

Bakker PAHM, Bakker AW, Marugg JD, Weisbeek PJ, Schippers B (1987) Bioassay for studying the role of siderophores in potato growth stimulation by Pseudomonas spp in short potato rotations. Soil Biol Biochem 19, 443-449

Bakker PAHM, Van Peer R, Schippers B (1990) Specificity of siderophores and siderophore receptors and biocontrol by Pseudomonas spp. In: Biological control of soil-borne plant pathogens (D Hornby, ed) CAB International, 131-142

Bakker PAHM, Van Peer R, Schippers B (1991) Suppression of soil-borne plant pathogens by fluorescent pseudomonads: mechanisms and prospects. In: Development in agriculturally managed-forest ecology (Beemster ABR, Bollen GJ, Gerlagh $M$, Ruissen MA, Schippers B, Tempel A, eds) Elsevier, Amsterdam 23, 217-230

Bates ML, Stanghellini ME (1984) Root rot of hydroponically grown spinach caused by Pythium aphanidermatum and Pythium dissocotum. Plant Dis 68, 989-991

Becker JO, Cook RJ (1988) Role of siderophores on suppression of Pythium species and production of increased-growth response of wheat by fluorescent pseudomonads. Phytopathology 78, 778-782

Becker JO, Hedges RW, Messens E (1985) Inhibitory effect of pseudobactin on the uptake of iron by higher plants. Appl Environ Microbiol 49, 1090-1093

Benians GJ, Barber DA (1974) The uptake of phosphate by barley plants from soil under aseptic and non-sterile conditions. Soil Biol Biochem 6, 195-200

Bienfait HF (1986) Iron efficiency relations of monocotyledonous and dicotyledonous plants. In: Iron, siderophores and plant diseases (TR Swinburne, ed) Plenum Press, New York, 21-27 
Bitter W, Marugg JD, de Weger LA, Tommassen J, Weibeek PJ (1991) The ferric-pseudobactin receptor PupA of Pseudomonas putida WCS358: homology to TonB-dependent Escherichia coli receptors and specificity of the protein. Mol Microbiol 5, 647655

Bossier P, Vestraete W (1986) Detection of siderophores in soil by a direct bioassay. Soil Biol Biochem 18, 481-486

Bowen GD, Rovira AD (1976) Microbial colonization of plant roots. Annu Rev Phytopathol 14, 121-144

Brisbane PG, Rovira AD (1988) Mechanisms of inhibition of Gaeumannomyces graminis var triciti by fluorescent pseudomonads. Plant Pathol 37, 104-111

Brisbane PG, Harris JR, Moen P (1989) Inhibition of fungi from wheat roots by Pseudomonas fluorescens 2-79 and fungicides. Soil Biol Biochem 21, 1019-1025

Broadbent P, Baker KF, Franks N, Holland J (1977) Effect of Bacillus spp on increased growth of seedlings in steamed and in non-treated soil. Phytopathology 67, 1027-1034

Brown ME (1974) Seed and root bacterization. Annu Rev Phytopathol 12, 181-197

Burr TJ, Schroth MN, Suslow T (1978) Increased potato yields by treatment of seedpieces with specific strain of Pseudomonas fluorescens and $P$ putida. Phytopathology 68, 1377-1383

Buyer JJ, Leong J (1986) Iron transport-mediated antagonism between plant growth-promoting and plant-deleterious Pseudomonas strains. $J$ Biol Chem 261, 791-794

Buyer JS, Wright JM, Leong J (1986) Structure of pseudobactin A214, a siderophore from a beandeleterious Pseudomonas. Biochemistry 25, 54925499

Buyer JS, Sikora LJ, Kratzke M (1990) Monoclonal antibodies to ferric pseudobactin, the siderophore of plant growth-promoting Pseudomonas putida B10. Appl Environ Microbiol 56, 419-424

Caesar AJ, Burr TJ (1987) Growth promotion of apple seedlings and rootstocks by specific strains of bacteria. Phytopathology 77, 1583-1588

Chao WL, Nelson EB, Harman GE, Hoch HC (1986) Colonization of the rhizosphere by biological control agents applied to seeds. Phytopathology 76, 60-64

Chao WL, Li KR, Chang WT (1988) Effect of root agglutinin on microbial activities in the rhizosphere. App/ Environ Microbiol 54, 1838-1841

Colyer PD, Mount MS (1984) Bacterization of potato with Pseudomonas putida and its influence on post harvest soft rot diseases. Plant Dis 68, 703-706

Compeau G, Al-Achi BJ, Platsouka E, Levy SB (1988) Survival of rifampin-resistant mutants of Pseudomonas fluorescens and Pseudomonas putida in soil systems. App/ Environ Microbiol 54, 2432-2438

Cook RJ, Sitton JW, Waldher JT (1980) Evidence via Pythium as pathogen of direct-drilled wheat in the Pacific Northwest. Plant Dis 64, 102-103
Cook RJ, Sitton JW, Haglund WA (1987) Increased growth and yield responses of wheat to reductions in the Pythium population by soil treatments. Phytopathology 77, 1192-1198

Cooper R (1959) Bacterial fertilizers in the Soviet Union. Soils Fertil 22, 327-333

Crowley E, Reid CPP, Szaniszlo PJ (1987) Microbial siderophores as iron sources for plants. In: Iron transport in microbes plants and animals (G Winkelmann, D Van der Helm, JB Neilands, eds) VCH, Weinheim, 375-385

Curl EA (1982) The rhizosphere: relation to pathogen behaviour and root disease. Plant Dis 66, 624-630

Currier TC, Szwara JE, Mclntyre JL (1988) The development of a Pseudomonas fluorescens product (Dager ${ }^{T M} \mathrm{G}$ ) for the control of Pythium and Rhizoctonia of cotton. In: Proceedings beltwide cotton production research conferences. National Cotton Council, Memphis, TN, 18-19

Davies KG, Whitebread R (1989) Factors affecting the colonization of a root system by fluorescent pseudomonads: the effects of water, temperature and soil microflora. Plant Soil 116, 247-256

Defago G, Haas D (1990) Pseudomonads as antagonists of soilborne plant pathogens: mode of action and genetic analysis. In: Soil biochem (JM Bollag, G Stotzky, eds) 6, 249-291

Defago G, Haas D, Berling CH, Burger U, Keel C, Voisard C, Wirthner P, Wuthrich B (1990) Suppression of black root rot of tobacco and other root diseases by strains of Pseudomonas fluorescens: potential applications and mechanisms. In: Biological control of soil-borne plant pathogens (D Hornby, ed), $\mathrm{CAB}$ Int, 93-108

Dickson JS, Koohamaraie M (1989) Cell surface charge characteristics and their relationship to bacterial attachment to meat surfaces. Appl Environ Microbiol 55, 832-836

Digat B (1991) A new encapsulation technology for bacterial inoculants and seed bacterization. In: Plant growth-promoting rhizobacteria-progress and prospects (C Keel, B Koller, G Defago, eds) IOBC/ WPRS, XIV/8, 383-391

Digat B, Mattar J (1990) Effects of temperature on growth and siderophore production of Pseudomonas fluorescens-putida strains. Symbiosis 9, 307-313

Digat B, Caille C, Guignebault P, Trillot M (1988) Pommier. Fertilisation bactériologique. Infos-CTIFL 41, 8-12

Digat B, Gaudillat M, Labadie JM (1990) Susceptibility of various tomato and lettuce genotypes to plantgrowth-promoting Pseudomonas. Symbiosis 9, 295303

Dommergues Y, Mangenot F (1990) Écologie microbienne du sol. Masson, Paris, $796 \mathrm{p}$

Duijff BJ, Meijer JW, Bakker PAHM, Schippers B (1991) Suppression of Fusarium wilt of carnation of Pseudomonas in soil; mode of action. In: Plant growth-promoting rhizobacteria-progress and prospects (C Keel, B Koller, G Defago, eds) IOBC/ WPRS, XIV/8, 152-156 
Dupler M, Baker R (1984) Survival of Pseudomonas putida, a biological control agent in soil. Phytopathology 75, 1047-1052

Duss F, Mozafar A, Oertli JJ, Jaeggi W (1986) Effect of bacteria on the iron uptake by axenically cultured roots of Fe-efficient and Fe-inefficient tomatoes ( $\mathrm{Ly}$ copersicon esculentum Mill). J Plant Nutr 9, 587598

Ecklund E (1970) Secondary effects of pseudomonads in the rhizoplan of peat grown cucumber plants. Acta Agric Scand suppl 17, 1s-57s

Elad Y, Baker R (1985) The role of competition for iron and carbon in suppression of chlamydospore germination of Fusarium spp by Pseudomonas spp. Phythopathology 75, 1053-1059

Elad Y, Chet I (1987) Possible role of competition for nutrients in biocontrol of Pythium damping-off by bacteria. Phytopatholgy 77, 190-195

Elad Y, Chet I, Baker R (1987) Increased growth response of plants induced by rhizobacteria antagonistic to soilborne fungi. Plant Soil 98, 325-330

Elliott LF, Lynch JM (1984) Pseudomonads as a factor in the growth of winter wheat (Triticum aestivum $\mathrm{L}$ ). Soil Biol Biochem 16, 69-71

Emery T (1965) Isolation, characterization and properties of fusarinine a hydroxamic acid, derivate of ornithine. Biochemistry 4, 1410-1417

Favrin RJ, Rahe JE, Mauza B (1988) Pythium spp associated with crown rot of cucumbers in British Columbia greenhouses. Plant Dis 72, 683-687

Fett WF, Osman SF, Dunn MF (1989) Characterization of exopolysaccharides produced by a plantassociated fluorescent pseudomonad. Appl Environ Microbiol 55, 579-583

Flaishman M, Eyal Z, Voisard C, Haas S (1990) Suppression of Septoria tritici by phenazine- or siderophore- deficient mutants of Pseudomonas. Curr Microbiol 20, 121-124

Foster RC, Rovira AD (1978) The ultrastructure of the rhizosphere of Trifolium subterraneum L. In: Microbial ecology (MW Loutit, JAR Miles, eds) SpringerVerlag, Berlin, 278-290

Fravel DR (1988) Role of antibiosis in the biocontrol of plant diseases. Annu Rev Phytopathol 26, 75-91

Funck-Jensen D, Hockenull J (1983) The influence of some factors on the severity of Pythium root rot of lettuce in soilless (hydroponic) culture growing systems. Acta Hortic 133, 129-136

Ganesan P, Gnanamanickam JJ (1987) Biological control of Sclerotium rolfsii Sacc in peanut by inoculation with Pseudomonas fluorescens. Soil Biol Biochem 19, 35-38

Garbaye J, Bowen GD (1987) Effect of different microflora on the success of ectomycorrhizal inoculation of Pinus radiata. Can J For Res 17, 941-943

Gardner JM, Chandler JL, Feldman AW (1984) Growth promotion and inhibition by antibiotic producing fluorescent pseudomonads on citrus roots. Plant Soil $77,103-119$
Geels FP, Schippers B (1983) Reduction of yield depressing in high frequency potato cropping soil after seed tuber treatment with antagonistic fluorescent Pseudomonas spp. Phytopathol Z 108, 207214

Geels FP, Lamers JG, Hoekstra O, Schippers B (1986) Potato plant response to seed tuber bacterization in the field in various rotations. Neth J Plant Pathol 92, 257-272

Gerretsen FC (1948) The influence of microorganisms on the phosphate intake by the plant. Plant Soil 1, $51-81$

Gill PR, Warren GJ (1988) An iron-antagonized fungistatic agent that is not required for iron assimilation from a fluorescent rhizosphere pseudomonad. $J$ Bacteriol 170, 163-170

Glandorf DCM, Bakker PAHM, Schippers B (1991) Crop specificity of fluorescent pseudomonads and the involvement of root agglutinins. In: Biotic interactions and soil-borne diseases (ABR Beemster, M Gerlagh, MA Ruissen, B Schippers, A Tempel, eds) Dev Agric Managed For Ecol 23, Elsevier, Amsterdam, 365-369

Grimes HD, Mount MS (1987) Influence of Pseudomonas putida on nodulation of Phaseolus vulgaris. Soil Biol Biochem 6, 27-30

Gurusiddaiah S, Weller DM, Sarkar A, Cook RJ (1986) Characterization of an antibiotic produced by a strain of Pseudomonas fluorescens inhibitory to Gaeumannomyces graminis var triciti and $P y$ thium spp. Antimicrob Agents Chemother 29, 488495

Gutterson NI, Layton TS, Ziegle JS, Warren GS (1986) Molecular cloning of genetic determinants for inhibition of fungal growth by a fluorescent pseudomonad. J Bacteriol 165, 696-703

Gutterson NI, Ziegle JS, Warren GJ, Layton TJ (1988) Genetic determinants for catabolite induction for antibiotic biosynthesis in Pseudomonas fluorescens HV37a. J Bacteriol 170, 380-385

Hamdan H, Thomashow LD, Weller DM (1988) Relative importance of fluorescent siderophore and phenazine antibiotic by Pseudomonas fluorescens 2-79 in suppression of take-all. Phytopathology 78 , 1522

Haynes WC, Stodola FH, Locke JM, Pridham TG, Conway HF, Sohns VE, Jackson RW (1956) Pseudomonas aureofasciens Kluyver and phenazine- $\alpha$ carboxylic acid, its characteristic pigment. $J$ Bacteriol 72, 412-417

Heming BC (1986) Microbial-iron interactions in the plant rhizosphere. An overview. J Plant Nutr 9, 505-521

Höfte M, Boelens J, Vestraete W (1991) Seed protection and promotion of seedling emergence by the plant growth beneficial Pseudomonas strain 7NSK2 and ANP15. Soil Biol Biochem 23, 407-410

Hohnadel D, Meyer JM (1988) Specificity of pyoverdin-mediated iron uptake among fluorescent $P$ seudomonas strains. J Bacteriol 70, 4865-4873 
Howell CR, Stipanovic RD (1979) Control of Rhizoctonia solani on cotton seedlings with Pseudomonas fluorescens and with an antibiotic produced by the bacteria. Phytopathology 69, 480-482

Howell CR, Stipanovic RD (1980) Suppression of Pythium ultimum induced damping off of cotton seedlings by Pseudomonas fluorescens and its antibiotic, pyoluteorin. Phytopathology 70, 712-715

Howell CR, Okon Y (1987) Recent results of greenhouse and field trials on bacterial-induced plant growth promotion with no obvious symptoms of plant disease. In: Proc Int Workshop PGPR. Ontario, Canada, 29-33

Howie WJ, Suslow TV (1986) Effect of antifungal compound biosynthesis on cotton root colonization and Pythium suppression by a strain of Pseudomonas fluorescens and its antifungal minus isogenic mutant. Phytopathology 76, 1069 (abstract)

Howie WJ, Cook RJ, Weller DM (1987) Effects of soil matric potential and cell mobility on wheat root colonization by fluorescent pseudomonads suppressive to take-all. Phytopathology 77, 286-292

Hoy JW, Schneider RW (1988) Role of Pythium in sugar cane stubble decline: effects on plant growth in field soil. Phytopathology 78, 1692-1696

Jackson RM, Brown ME, Burlingham SK (1964) Similar effects on tomato plants of Azotobacter inoculation and application of gibberelines. Nature 203, 851-852

James DW, Suslow TV, Steinback KE (1985) Relationship between rapid, firm adhesion and longterm colonization of roots by bacteria. Appl Environ Microbiol 50, 392-397

Jasalavich CA, Anderson AJ (1981) Isolation from legume tissue of an agglutinin of saprophytic pseudomonads. Can J Bot 59, 264-271

Kanner D, Gerber NN, Bartha R (1978) Pattern of phenazine pigment production by a strain of $\mathrm{PSeu}$ domonas aeruginosa. J Bacteriol 134, 690-692

Keel C, Voisard C, Berling CH, Kahr G, Defago G (1989) Iron sufficiency a prerequisite for the suppression of tobacco black root rot by Pseudomonas fluorescens $\mathrm{CHAO}$ in gnotobiotic conditions. Phytopathology 79, 584-589

Keel C, Wirthner P, Oberhansli TH, Voisard C, Burger $U$, Haas D, Defago G (1990) Pseudomonads as antagonists of plant pathogens in the rhizosphere: role of the antibiotic 2,4-diacetylphloroglucinol in the suppression of black root rot of tobacco. Symbiosis $9,327-341$

Keel C, Maurhofer M, Oberlhansli TH, Voisard C, Haas D, Defago G (1991) Role of 2,4diacetylphloroglucinol in the suppression of take-all of wheat by a strain of Pseudomonas fluorescens. In: Biotic interactions and soil-borne diseases (Beemster ABR, Bollen GJ, Gerlagh M, Ruissen MA, Schippers B, Tempel A) Dev Agric Managed Forest Ecol 23, Elsevier, Amsterdam, 335-338

Kerr A (1972) Biological control of crown gall: seed inoculation. J App/ Bacterio/ 35, 493-497
Kloepper JW, Schroth MN (1978) Plant growthpromoting rhizobacteria on radishes. In: Proc Int Conf Plant Pathol Bact Angers, 379-382

Kloepper JW, Schroth MN (1981a) Development of a powder formulation of rhizobacteria for inoculation of potato seed pieces. Phytopatholgy 71, 590-592

Kloepper JW, Schroth MN (1981b) Plant growthpromoting rhizobacteria and plant growth under gnotobiotic conditions. Phytopathology 71, 642-664

Kloepper JW, Schroth MN (1981c) Relationship of in vitro antibiosis of plant growth-promoting rhizobacteria to plant growth and displacement of root microflora. Phytopathology 71, 1020-1023

Kloepper JW, Leong J, Teintze M, Schroth MN (1980a) Enhanced plant growth by siderophores produced by plant growth promoting rhizobacteria. Nature 286, 885-886

Kloepper JW, Leong J, Teintze M, Schroth MN (1980b) Pseudomonas siderophores: a mechanism explaining disease suppressive soils. Curr Microbiol 4, 317-320

Kloepper JW, Schroth MN, Miller TD (1980c) Effects of rhizosphere colonization by plant growth promoting rhizobacteria on potato plant development and yield. Phytopathology 70, 1078-1082

Kloepper JW, Scher FM, Laliberte M, Tipping B (1986) Emergence-promoting rhizobacteria: description and implications for agriculture. In: Iron, siderophores and plant diseases (TR Swinburne, ed) NATO ASI Series A, Life Sci, Plenum Press, New York, 351, 155-164

Kloepper JW, Hume DJ, Scher FM, Singleton C, Tipping B, Laliberte M, Frauley K, Kutchaw T, Simonson C, Lifshitz R, Zaleska I, Lee L (1988) Plant growth-promoting rhizobacteria on canola (rapeseed). Plant Dis 72, 42-46

Knowles CJ (1976) Microorganisms and cyanids. Bacteriol Rev 40, 652-680

Korhonen TK, Tarkka E, Ranta H, Haahtela K (1983) Fimbriae of Klebsiella sp: molecular characterization and role in bacterial adhesion to plant root. $J$ Bacteriol 155, 860-865

Krasilnikov M (1961) On the role of soil bacteria in plant nutrition. J Gen App/Microbio/ 7, 128-144

Kraus J, Loper JE (1991) Biocontrol of Pythium damping-off of cotton and cucumber by Pseudomonas fluorescens Pf-5: mechanistic studies. In: Plant growth-promoting rhizobacteria-progress and prospects (C Keel, B Koller, G Defago, eds) IOBC/ WPRS XIV/8, 172-176

Kuc J, Shockley G, Kearney K (1975) Protection of cucumber against Colletotrichum lagenarium by Colletotrichum lagenarium. Physiol Plant Pathol 7, 195199

Leben SD, Wadi JA, Easton GD (1987) Effects of Pseudomonas fluorescens on potato plant growth and control of Verticillium dahliae. Phytopathology $77,1592-1595$

Leeman M, Scheffer RJ, Schippers B (1991) Control of fusarium wilt of radish by Pseudomonas fluores- 
cens WCS374, in greenhouse trials. In: Plant growth-promoting rhizobacteria-progress and prospects (C Keel, B Koller, G Defago, eds) IOBC/ WPRS, XIV/8, 34-38

Leisinger T, Margraff R (1979) Secondary metabolites of pseudomonads. Microbiol Rev 43, 422-442

Lemanceau P (1988) Réceptivité des sols aux fusarioses vasculaires : étude critique des théories proposées. Thèse de doctorat, univ Claude bernard, Lyon, $99 p$

Lemanceau P, Samson R (1983) Relations entre quelques caractéristiques in vitro de 10 Pseudomonas fluorescents et leur effet sur la croissance du haricot (Phaseolus vulgaris $\mathrm{L}$ ). In : Les antagonismes microbiens, $24^{e}$ colloque SFP Bordeaux INRA, 327-328

Lemanceau P, Alabouvette C (1991) Biological control of Fusarium diseases by fluorescent Pseudomonas and non-pathogenic Fusarium. Crop Protec 10, 279-286

Lemanceau P, Alabouvette C, Meyer JM (1986) Production of fusarinine and iron assimilation by pathogenic and non-pathogenic Fusarium. In: Iron siderophores and plant diseases (TR Swinburne, ed) Plenum press, New York, 251-253

Lemanceau P, Alabouvette C, Couteaudier Y (1988a) Recherches sur la résistance des sols aux maladies. XIV. Modification du niveau de réceptivité d'un sol résistant et d'un sol sensible aux fusarioses vasculaires en réponse à des apports de fer et de glucose. Agronomie 8, 155-162

Lemanceau P, Samson R, Alabouvette C (1988b) Recherches sur la résistance des sols aux maladies. XV. Comparaison des populations de Pseudomonas fluorescents dans un sol résistant et un sol sensible aux fusarioses vasculaires. Agronomie 8, 243249

Leong $J$ (1986) Siderophores: their biochemistry and possible role in the biocontrol of plant pathogens. Annu Rev Phytopathol 24, 187-208

Leong J, Bitter W, Koster M, Marugg JD, Weisbeek PJ (1991) Genetics of iron transport in plant growthpromoting Pseudomonas putida WCS358. In: The rhizosphere and plant growth (DL Keister, PB Gregan, eds) Kluwer Acad Publ, 271-278

Libbert E, Kaiser W, Kunert R (1969) Interactions between plants and epiphytic bacteria regarding their auxin metabolism. VI. The influence of the epiphytic bacteria on the component of extractable auxin in the plant. Physiol Plant 22, 432-439

Liddel CM, Parke JL (1989) Enhanced colonization of pea taproots by a fluorescent pseudomonad biocontrol agent by water infiltration into soil. Phytopathology $79,1327-1332$

Lifshitz R, Kloepper JW, Scher FM, Tipping EM, Laliberte $M$ (1986) Nitrogen fixing pseudomonads isolated from roots of plant grown in the Canadian High Arctic. Appl Environ Microbiol 51, 251-255

Lifshitz R, Kloepper JW, Kozlowski M, Simonson C, Carlson J, Tipping EM, Zaleska I (1987) Growth promotion of canola (rapeseed) seedlings by a strain of Pseudomonas putida under gnotobiotic conditions. Can J Microbiol 33, 390-395

Linberg GO (1981) An antibiotic lethal to fungi. Plant Dis 65, 680-683

Linderman RG, Paulitz TC (1990) Mycorrhizalrhizobacterial interactions. In: Biological control of soil-borne plant pathogens (D Hornby, ed) CAB, Int, 261-283

Lindsay WL (1974) Role of chelation in micronutrient availability. In: The plant root and its environment (EW Carson, ed) University Press, of Virginia, Charlottesville, 507-524

Lindsay WL, Schwab B (1981) The chemistry of iron in soils and its availability to plants. J Plant Nutr 5 , 821-840

Lockwood JL (1981) Exploitation competition. In: The fungal community. Its organisation and role in the ecosystem (DT Wicklow, GC Carrol, eds) M Dekker, Inc, $833 \mathrm{p}$

Loper JE (1988) Role of fluorescent siderophore production in biological control of Pythium ultimum by a Pseudomonas fluorescens strain. Phytopathology $78,166-172$

Loper JE, Schroth MN (1986a) Importance of siderophores in microbial interactions in the rhizosphere. In: Iron siderophores and plant disease (TR Swinburne) Plenum Press, New York, 85-98

Loper JE, Schroth MN (1986b) Influence of bacterial sources of indole-3-acetic acid on root elongation of sugar beet. Phytopathology 76, 386-389

Loper JE, Buyer JS (1991) Siderophores in microbial interactions on plant surfaces. Mol Plant-Microbe Interac 4, 5-13

Loper JE, Haack C, Schroth MN (1985) Populations dynamics of soil pseudomonads in the rhizosphere of potato (Solanum tuberosum L). Appl Environ Microbiol 49, 416-422

Lynch JM (1976) Products of soil microorganisms in relation to plants growth. CRC Crit Rev Microbio/ 5, $67-107$

Mamoun M, Olivier JM (1992) Effect of soil pseudomonads on colonisation of hazel roots by ectomycorrhizal species Tuber melanosporum and its competitors. Plant Soil 139, 265-273

Marugg JD, Van Spanje M, Hoekstra WPM, Schippers B, Weisbeek JP (1985) Isolation and analysis of genes involved in siderophore biosynthesis in plant growth-stimulating Pseudomonas putida WCS358. J Bacteriol 164, 563-570

Marugg JD, Weger LA (de), Neilander HB, Oorthuizen $M$, Recourt K, Lugtenberg B, Van der Hofstad GAHM, Weisbeek PJ (1989) Cloning and characterization of a gene encoding an outer membrane protein required for siderophore-mediated uptake of $\mathrm{Fe}^{3+}$ in Pseudomonas putida WCS358. J Bacteriol 171, 2819-2826

Maurhofer M, Keel C, Schnider U, Haas D, Defago G (1991) Does enhanced antibiotic production in Pseudomonas fluorescens strain $\mathrm{CHAO}$ improve its dis- 
ease suppressive capacity? In: Plant growthpromoting rhizobacteria-progress and prospects (C Keel, B Koller, G Defago, eds) IOBC/WPRS, XIV/8, 201-202

Mcinroy JA, Kloepper JW (1991) Analysis of populations densities and identification of endophytic bacteria of maize and cotton in the field. In: Plant growth-promoting rhizobacteria-progress and prospects (C Keel, B Koller, G Defago, eds) IOBC/ WPRS, XIV/8, 328-331

Mench M (1985) Influence des exsudats racinaires solubles sur la dynamique des métaux dans la rhizosphère du maïs (Zea mays $L$ ). Thèse de Dr de I'INPL, Univ Nancy, $109 \mathrm{p}$

Mew TW, Rosales AM (1986) Bacterization of rice plants for control of sheath blight caused by Rhizoctonia solani. Phytopathology 76, 1260-1264

Meyer JM, Abbdallah MA (1978) The fluorescent pigment of Pseudomonas fluorescens: biosynthesis, purification and physico-chemical properties. $J$ Gen Microbiol 107, 319-328

Meyer JM, Halle F, Hohnadel D, Lemanceau P, Ratefiarivelo H (1987) Siderophores of Pseudomonas: biological properties. In: Iron transport in microbes, plants and animals (D Van der Helm, J Neilands, G Winkelmann, eds) VCH, Weinheim, 189-205

Meyer JR, Linderman RG (1986) Response of subterranean clover to dual inoculation with vesiculararbuscular mycorrhizal fungi and a plant growthpromoting bacteria, Pseudomonas putida. Soil Biol Biochem 18, 185-190

Mircetich SM (1971) The role of Pythium in feeder roots of diseased and symptomless peach trees and in ochard soils in peach tree decline. Phytopathology 61, 357-361

Misaghi IJ, Stowell LS, Grogan RG, Spearman LC (1982) Fungistatic activity of water-soluble fluorescent pigments of pseudomonads. Phytopathology $72,33-36$

Misaghi IJ, Olsen MW, Cotty PJ, Donndelinger CR (1988) Fluorescent siderophore mediated iron deprivation. A contingent biological control mechanism. Soil Biol Biochem 20, 573-574

Mishutin EM, Naumova AN (1962) Bacteria fertilizers, their effectiveness and mode of action. Mikrobiologiya 31, 543-555

Morel JL, Bitton G, Chaudry GR, Awong J (1989) Fate of genetically modified microorganisms in the corn rhizosphere. Curr Microbiol 18, 355-360

Neilands JB (1973) Microbial iron transport compounds (siderochromes). In: Inorganic biochemistry (GL Eichorn) Elsevier, Amsterdam, 167-202

Neilands JB, Leong SA (1986) Siderophores in relation to plant growth and disease. Annu Rev Plant Physiol 37, 187-208

Okon $Y$ (1985) Azospirillum as a potential inoculant for agriculture. Trends Biotechnol 3, 223-228

Oliveira E, Sieverding E, Toros (1987) Interaction between three species of VAM fungi and an isolate of
Pseudomonas putida on cassava. In: Proc 7 th North Am Conf Mycorrhizae (DM Sylvia, LL Hung, JH Graham, eds) Univ Florida, Gainesville, FL 216

Olivier JM, Guillaumes J (1981) Essais de lutte biologique contre la tache bactérienne. Mush Sci XI, 353-367

Paau AS (1989) Formulations useful in applying beneficial microorganisms to seeds. Trends Biotechnol 6, 276-279

Park CS, Paulitz TC, Baker R (1988) Biocontrol of Fusarium wilt of cucumber resulting from interactions between Pseudomonas putida and non-pathogenic isolates of Fusarium oxysporum. Phytopathology 78, 190-194

Parke JL, Moen R, Rovira AD, Bowen GD (1986) Soil water flow affects rhizosphere distributions of a seed born biological control agent, Pseudomonas fluorescens. Soil Biol Biochem 18, 583-588

Pierson EA, Weller DM (1991) Recent work on control of take-all of wheat by fluorescent pseudomonads. In: Plant growth-promoting rhizobacteria-progress and prospects (C Keel, B Koller, G Defago, eds) IOBC/WPRS, XIV/8, 96-97

Pierson III LS, Thomashow LS (1991) Analysis of phenazine antibiotic production by Pseudomonas aureofasciens strain 30-84. In: Plant growthpromoting rhizobacteria-progress and prospects (C) Keel, B Koller, G Defago, eds) IOBC-WPRS, XIV/8, 119-121

Polonenko DR, Scher FM, Kloepper JW, Singleton CA, Laliberté EM, Zaleska I (1987) Effects of root colonizing bacteria on nodulation of soybean roots by Bradyrhizobium japonicum. Can J Microbiol 33, 498-503

Powell PE, Cline GR, Reid CPP, Szaniszlo PJ (1980) Occurrence of hydroxamate siderophore iron chelators in soils. Nature 287, 833-834

Powell PE, Szaniszlo PJ, Cline GR, Reid CPP (1982) Hydroxamate siderophores in the nutrition of plants. $J$ Plant Nutr 5, 653-673

Powell PE, Szanizslo PJ, Reid CPP (1983) Confirmation of occurence of hydroxamate siderophores in soil by a novel Escherichia coli bioassay. Appl Environ Microbio/ 46, 1080-1083

Raj J, Bagyaraj DJ, Manjunath A (1981) Influence of soil inoculation with vesicular-arbuscular mycorrhiza and a phosphate-dissolving bacterium on plant growth and 32P-uptake. Soil Biol Biochem 13, 105-108

Reid RK, Reid CPP, Szaniszlo PJ (1984) Comparaison of siderophore concentrations on aqueous extracts of rhizosphere and adjacent bulk soil. Pedobiologia 26, 263-266

Rhodes DJ, Logan C (1986) Effects of fluorescent pseudomonads on potato blackleg syndrome. Ann Appl Biol 108, 511-518

Rivière J (1966) Action des micro-organismes de la rhizosphère sur la croissance du blé. III. Isolement et identification des bactéries dégradant l'acide indole-3-acétique. Ann Inst Pasteur 111, 250-256 
Roseinweig WD, Stotzky G (1979) Influence of environmental factors on antagonism of fungi by bacteria in soil: clay minerals and pH. Appl Environ Microbio/ 38, 1120-1126

Rosenweig WD, Stotzky G (1980) Influence of environmental factors on antagonism of fungi by bacteria in soil: nutrient levels. App/ Environ Microbio/ 39, 354360

Rovira AD (1972) Studies on the interactions between plant roots and micro-organisms. J Aust Inst Agric Sci $90-94$

Rovira AD, Davey CB (1971) Biology of the rhizosphere. In: The plant root and its environment (EW Carson, ed) Univ Press Virginia, Charlottesville, 153-204

Sakthivel N, Gnanamanickam SS (1987) Evaluation of Pseudomonas fluorescens for suppression of sheath rot disease and for enhancement of gain yields in rice (Oryza sativa L). App/ Environ Microbiol 53, 2056-2059

Sakthivel E, Sivamani E, Unnamalai N, Gnanamanickam SS (1986) Plant growth-promoting rhizobacteria in enhancing plant growth and suppressing plant pathogens. Curr Sci (Bangalore) 55, 22-25

Salt GA (1979) The increasing interest in minor pathogens. In: Soilborne plant pathogens (B Schippers, W Gams, eds) Acad Press, Londres, 289-312

Scher FM, Baker R (1982) Effect of Pseudomonas putida and a synthetic iron chelator on induction of suppressiveness to Fusarium-wilt pathogens. Phytopathology 72, 1567-1573

Scher FM, Kloepper JW, Singleton CA (1985) Chemotaxis of fluorescent Pseudomonas spp to soybeans seed exsudates in vitro and in soil. Can J Microbiol 31, 570-574

Scher FM, Kloepper JW, Singleton C, Zaleska I, Laliberte $M$ (1988) Colonization of soybean roots by Pseudomonas and Serratia species: relationship to bacterial motility, chemotaxis, and generation time. Phytopathology 78, 1055-1059

Schippers B, Geels FP, Hoekstra O, Lamers JG, Maenhout CAAA, Scholte K (1985) Yield depressions in narrow rotations caused by unknown microbial factors and their suppression by selected pseudomonads. In: Ecology and management of soilborne plant pathogens (CA Parker, AD Rovira, KJ Moore, PTW Wong, JF Kollmorgen eds) HPS, St Paul, 127-130

Schippers B, Bakker AW, Bakker PAHM (1987) Interactions of deleterious and beneficial rhizosphere microorganisms and the effect of cropping practices. Annu Rev Phytopathol 25, 339-358

Schroth MN, Hildenbrand DC (1964) Influence of plant exsudates on root-infecting fungi. Annu Rev Phytop athol 2, 101-132

Schroth MN, Hancock JG (1981) Selected topics in biological control. Annu Rev Microbiol 34, 453-476

Schroth MN, Hancock JG (1982) Disease suppressive soil and root colonizing bacteria. Science 216 , 1376-1381
Segalen $P$ (1964) Le fer dans les sols. Orstom, Paris, $150 \mathrm{p}$

Simeoni LA, Lindsay WL, Baker R (1987) Critical iron level associated with biological control of Fusarium wilt. Phytopathology 77, 1057-1061

Sneh B, Dupler M, Elad Y, Baker R (1984) Chlamydospores germination of Fusarium oxysporum $f \mathrm{sp}$ cucumerinum as affected by fluorescent and lytic bacteria from Fusarium-suppressive soil. Phytopathology 74, 1115-1124

Stanghellini ME, Kronland WC (1986) Yield loss in hydroponically grown lettuce attributed to subclinical infection of feeder rootlets by Pythium dissocotum. Plant Dis 70, 1053-1056

Stanghellini ME, White JG, Tomlinson JA, Clay C (1988) Root rot of hydroponically grown cucumbers caused by zoospore producing isolates of Pythium intermedium. Plant Dis 72, 358-359

Strzelczyk E, Kampert M, Dahm H (1973) Production and decomposition of indole acetic acid (IAA) by microorganisms isolated from the root zone of two crop plants. Acta Microbiol Pol, Ser B5 (22), $71-79$

Stutz EW, Defago G, Kern H (1986) Naturally occuring fluorescent pseudomonads involved in suppression of black root rot of tobacco. Phytopathology 76, 181-185

Stutz E, Kahr G, Defago G (1989) Clays involved in suppression of tobacco black root rot by a strain of Pseudomonas fluorescens. Soil Biol Biochem 21, 361-366

Suslow TV (1982) Role of root colonizing bacteria in plant growth. In: Phytopathogenic prokaryotes (MS Mount, GH Lacy, eds) Acad Press, Londres, 187223

Suslow TV, Schroth MN (1982a) Role of deleterious rhizobacteria as minor pathogens in reducing crop growth. Phytopathology 72, 111-115

Suslow TV, Schroth MN (1982b) Rhizobacteria of sugarbeet: effects of seed application and root colonization on yield. Phytopathology 72, 199-206

Suty A, Lemanceau P, Alabouvette C (1992) Les Pythium spp agents de pertes de racines en culture hors-sol. In: Integrated and biological control in protected crop ( $R$ Cavalloro) OILB/OEPP, $6 \mathrm{p}$ (sous presse)

Teintze M, Hossain MB, Barnes CL, Leong J, Van der Helm D (1981) Structure of ferripseudobactin, a siderophore from plant growth promoting Pseudomonas B10. Biochemistry 20, 6446-6457

Thomashow LS (1991) Molecular basis of antibiosis mediated by rhizosphere pseudomonads. In: Plant growth-promoting rhizobacteria-progress and prospects (C Keel, B Koller, G Defago, eds) IOBC/ WPRS, XIV/8, 109-115

Thomashow LS, Weller DM (1988) Role of a phenazine antibiotic from Pseudomonas fluorescens in biological control of Gaeumannomyces graminis var tritici. J Bacteriol 170, 3499-3508 
Thomashow LS, Weller DM (1990) Application of fluorescent pseudomonads to control root diseases of wheat and some mechanisms of disease suppression. In: Biological control of soil-borne plant pathogens (D Hornby, ed) CAB Int, 109-122

Thomashow LS, Weller DM, Bonsall RF, Pierson III LS (1990) Production of antibiotic phenazine-1carboxylic acid by fluorescent Pseudomonas species in the rhizosphere of wheat. Appl Environ Microbiol 56, 908-912

Urinamalai N, Gnanamanickam SS (1984) Pseudomonas fluorescens in an antagonist to Xanthomonas citri (Hasse) Dye, the incitant of citrus canker. Curr Sci (Bangalore) 53, 703-704

Van der Hofstad GAJM, Marugg JD, Verjans GMGM, Weisbeek PJ (1986) Characterization and structu$\mathrm{ral}$ analysis of the siderophore produced by the PGPR Pseudomonas putida strain WCS358. in Iron, siderophores and plant diseases (TR Swinburne, ed) Plenum Press, New York, 71-75

Van Loosdrecht MCM, Lylkema J, Norden W, Schraa G, Zehnder A (1987) The role of bacterial cell wall hydrophobicity in adhesion. Appl Environ Microbiol 53, 1893-1897

Van Peer R, Schippers B (1989) Plant growth responses to bacterization with selected Pseudomonas spp strains and rhizosphere microbial development in hydroponic cultures. Can $J$ Microbiol 35, 456-463

Van Peer, Punte HLM, Weger LA (de), Schippers B (1990a) Characterization of root surface and endorhizosphere pseudomonads in relation to their colonization of roots. Appl Environ Microbiol 56, 24622470

Van Peer R, Van Kuik AJ, Rattink H, Schippers B (1990b) Control of Fusarium wilt in carnation grown on rockwool by Pseudomonas sp strain WCS417r and by Fe-EDDHA. Neth J Plant Patho/ 96, 119-132

Van Peer R, Niemann CJ, Schippers B (1991) Induced resistance and phytoalexin accumulation in biological control of Fusarium wilt of carnation by Pseudomonas sp strain WCS417r. Phytopathology $81,728-734$

Van Verseveld HW, Bakker P, Van der Woude T, Van der Woude T, Terleth C, Graaf FK (de) (1985) Production of fimbrial adhesins $\mathrm{K} 99$ and $\mathrm{F} 41$ by enterotoxigenic Escherichia coli as a function of growthrate domain. Infect Immun 49, 159-163

Vesper SJ (1987) Production of pili (fimbriae) by Pseudomonas fluorescens and correlation with attachment to corn roots. Appl Environ Microbiol 53, 1397-1403

Voisard C, Keel C, Haas D, Defago G (1989) Cyanide production by Pseudomonas fluorescens helps suppress black root rot of tobacco under gnotobiotic conditions. EMBO J 8, 351-358

Walther D, Gindrat D (1988) Biological control of damping off of sugar-beet and cotton with Chaetomium globosum and a fluorescent Pseudomonas. Can J Microbiol 34, 631-637
Weger LA (de) (1988) Role of bacterial cell surface in potato growth stimulation by fluorescent Pseudomonas bacteria. PhD Thesis, State Univ Leiden, PaysBas, $91 \mathrm{p}$

Weger LA (de), Van Boxtel R, Van der Burg B, Bruters RA, Geels FP, Schippers B, Lugtenberg B (1986) Siderophores and outer membrane proteins of antagonistic, plant growth stimulating, root colonizing Pseudomonas spp. J Bacteriol 165, 585-594

Weger LA (de) Van Vlugt CIM, Wijfjes AHM, Bakker PAHM, Schippers B, Lugtenberg B (1987) Flagella of a plant-growth-stimulating Pseudomonas fluorescens strain are required for colonization of potato roots. J Bacteriol 169, 2769-2773

Weger LA (de), Van Arendonk JJCN, Recourt K, Van der Hofstad GAJM, Weisbeek PJ, Lugtenberg B (1988) Siderophore-mediated uptake of $\mathrm{Fe}^{3+}$ by the plant growth stimulating Pseudomonas putida strain WCS358 and by other rhizosphere microorganisms. $J$ Bacteriol 170, 4693-4698

Weger LA (de), Van Loosdrecht MCM, Klaasen HE, Lugtenberg B (1989a) Mutational changes in physicochemical cell surface properties of plant growth stimulating Pseudomonas spp do not influence the attachment properties. J Bacteriol 171, 2756-2761

Weger LA (de), Bakker PAHM, Schippers B, Van Loosdrecht MCM, Lugtenberg B (1989b) Pseudomonas spp with mutational changes in the $\mathrm{O}$ antigenic side chain of their lipopolysaccharids are affected in their ability to colonize potato roots. In: Molecular signals in microbe-plant symbiotic and pathogenic systems (B Lugtenberg, ed) Plenum Press, New York, 197-202

Wei G, Kloepper JW, Tuzun S (1991) Induction of systemic resistance with seed treatment by PGPR strains. In: Plant growth-promoting-rhizobacteriaprogress and prospects (C Keel, B Koller, G Defago, eds) IOBCMPRS, XIV/8, 191-194

Weller DM (1986) Effects of wheat genotype on root colonization by a take-all suppressive strain of $P$ seudomonas fluorescens. Phytopathology 76, 1059

Weller DM (1988) Biological control of soilborne plant pathogens in the rhizosphere with bacteria. Annu Rev Phytopathol 26, 379-407

Weller DM, Cook RJ (1983) Suppression of take all of wheat by seed treatments with fluorescent pseudomonads. Phytopathology 73, 463-469

Weller DM, Cook RJ (1986) Increased growth of wheat by seed treatments with fluorescent pseudomonads, and implications of Pythium control. Can J Plant Pathol 8, 328-334

Weller DM, Howie WJ, Cook RJ (1988) Relationships between in vitro inhibition of Gaeumannomyces graminis var tritici and suppression of take all wheat by fluorescent pseudomonads. Phytopathology 78, 1094-1100

Wendenbaum S, Demange R, Dell A, Meyer JM, Abdallah MA (1983) The structure of pyoverdine $\mathrm{Pa}$, the siderophore of Pseudomonas aeruginosa. Tetrahedron Lett 24, 4877-4880 
Wessendorf J, Lingens F (1989) Effect of culture and soil conditions on survival of Pseudomonas fluorescens R1 in soil. App/ Microbiol Biotech 31, 97-102

Weststeijn EA, Meijer JW (1991) Suppression of Pythium root rot in tulips by fluorescent pseudomonads. In: Biotic interactions and soil-borne diseases (ABR Beemster, GJ Bollen, M Gerlagh, MA Ruissen, B Schippers, A Tempel) Develop Agric Manage-For Ecol 23, Elsevier, Amsterdam, 281-283

Willams ST, Vickers JC (1986) The ecology of antibiotic production. Microb Ecol 12, 43-52

Wong PTW, Baker R (1984) Suppression of wheat take-all and Ophiobolus patch by fluorescent pseudomonads from a Fusarium-suppressive soil. Soil Biol Biochem 16, 397-403
Xu GW, Gross DC (1986a) Selection of fluorescent pseudomads antagonistic to Erwinia carotovora and suppressive of potato seed piece decay. Phytopathology 76, 414-422

Xu GW, Gross DC (1986b) Field evaluations of the interactions among fluorescent pseudomonads, Erwinia carotorova, and potato yields. Phytopathology $76,423-430$

Yang C, Leong J (1984) Structure of pseudobactin 7SR1, a siderophore from a plant-deleterious Pseudomonas strain. Biochemistry 23, 3534-3540

Yuen GY, Schroth MN (1986) Interactions of Pseudomonas fluorescens strain E6 with ornamental plants and its effect on the composition of rootcolonizing microflora. Phytopathology 76, 176-180 